Eduard I. Dedkov • Tatiana Y. Kostrominova •

Andrei B. Borisov • Bruce M. Carlson

\title{
MyoD and myogenin protein expression in skeletal muscles of senile rats
}

Received: 9 July 2002 / Accepted: 26 November 2002 / Published online: 18 February 2003

(C) Springer-Verlag 2003

\begin{abstract}
We analyzed the level of protein expression of two myogenic regulatory factors (MRFs), MyoD and myogenin, in senile skeletal muscles and determined the cellular source of their production in young adult (4 months old), old (24, 26, and 28 months old), and senile (32 months old) male rats. Immunoblotting demonstrated levels of myogenin $\sim 3.2, \sim 4.0$, and $\sim 5.5$ times higher in gastrocnemius muscles of 24-, 26-, and 32month-old animals, respectively, than in those of young adult rats. Anti-MyoD antibody recognized two major areas of immunoreactivity in Western blots: a single MyoD-specific band ( 43-45 kDa) and a double (or triple) MyoD-like band ( 55-65 kDa). Whereas the level of MyoD-specific protein in the 43- to $45-\mathrm{kDa}$ band remained relatively unchanged during aging compared with that of young adult rats, the total level of MyoD-like immunoreactivity within the 55- to $65-\mathrm{kDa}$ bands was $\sim 3.4, \sim 4.7, \sim 9.1$, and $\sim 11.7$ times higher in muscles of 24-, 26-, 28-, and 32-month-old rats, respectively. The pattern of MRF protein expression in intact senile muscles was similar to that recorded in young adult denervated muscles. Ultrastructural analysis of extensor digitorum longus muscle from senile rats showed that, occasionally, the area of the nerve-muscle junction was partially or completely devoid of axons, and satellite cells with the
\end{abstract}

This work was financed by NIH (grant no. PO1-AG10821). T.Y. Kostrominova was supported by NIA research training grant no. T32-AG00116

E.I. Dedkov and T.Y. Kostrominova contributed equally to this work

E. I. Dedkov ( ) T. Y. Kostrominova · A. B. Borisov ·

B. M. Carlson

Department of Cell and Developmental Biology,

4643 Medical Sciences II Building, University of Michigan,

Ann Arbor, Michigan, 48109, USA

e-mail: ededkov@umich.edu

Tel.: +1-734-7632552

Fax: +1-734-7631166

T. Y. Kostrominova $\cdot$ B. M. Carlson

Institute of Gerontology, University of Michigan,

Ann Arbor, USA features of activated cells were found on the surface of living fibers. Immunohistochemistry detected accumulated MyoD and myogenin proteins in the nuclei of both fibers and satellite cells in 32-month-old muscles. We suggest that the up-regulated production of MyoD and myogenin proteins in the nuclei of both fibers and satellite cells could account for the high level of MRF expression in muscles of senile rats.

Keywords Aging - Skeletal muscles · Muscle fibers • Satellite cells $\cdot$ MyoD $\cdot$ Myogenin $\cdot$ Rat (WI/HicksCar)

\section{Introduction}

MyoD and myogenin are two members of a family of myogenic regulatory factors (MRFs) that also includes myf-5 and MRF-4 (Funk et al. 1991). MRFs act as transcription regulatory proteins by binding to the enhancer regions of numerous muscle-specific genes (Edmondson and Olson 1993). It was originally established that both MyoD and myogenin play a key role during embryonic and neonatal myogenesis (for a review, see Neville and Rosenthal, 1996). More recently, their crucial regulatory function has been discovered in the processes of plasticity, adaptation, and regeneration in adult muscle (for reviews, see Buonanno et al. 1998; Sabourin and Rudnicki 2000).

Although MyoD and myogenin are expressed at a relatively high level during the first month after birth, both MRFs are barely detectable in skeletal muscles of adult animals (Duclert et al. 1991; Eftimie et al. 1991; Witzemann and Sakmann 1991; Musaro et al. 1995). The expression of MyoD and myogenin mRNA increases in skeletal muscles of aged animals (Musaro et al. 1995; Marsh et al. 1997; Gomes and Booth 1998; Lowe et al. 1998; Kostrominova et al. 2000; Alway et al. 2001). However, the protein levels of these MRFs continue to be incompletely analyzed in old and, particularly, in senile skeletal muscle (Kostrominova et al. 2000; Tamaki et al. 2000; Alway et al. 2001, 2002; Dedkov et al. 2001). For 
example, despite the concurrence of the results of Kostrominova et al. (2000) and Alway et al. (2002) demonstrating that, in rat gastrocnemius muscle, the level of myogenin mRNA increases with aging, differences concerning the level of protein expression still remain between these studies.

Over the past decade, a number of experimental studies have indicated that the change in the level of MyoD and myogenin expression in both adult and senescent skeletal muscle might be provoked either by motor denervation (Duclert et al. 1991; Eftimie et al. 1991; Voytik et al. 1993; Weis 1994; Adams et al. 1995; Kostrominova et al. 2000; Dedkov et al. 2001) or by regeneration (Füchtbauer and Westphal 1992; Grounds et al. 1992; Kami et al. 1995; Koishi et al. 1995; Marsh et al. 1997; Creuzet et al. 1998; Cooper et al. 1999; Launay et al. 2001). In denervated and regenerating skeletal muscle, the up-regulation of these MRFs could occur in the nuclei of fibers and activated satellite cells (Füchtbauer and Westphal 1992; Grounds et al. 1992; Weis 1994; Koishi et al. 1995; Kami et al. 1995; Creuzet et al. 1998; DupontVersteegden et al. 1998; Cooper et al. 1999; Kostrominova et al. 2000; Dedkov et al. 2001; Launay et al. 2001). Nevertheless, only a few studies have attempted to determine the source of MyoD and myogenin protein expression in mature skeletal muscle by using techniques that allow the detection of the expression of MRF discretely in either muscle fiber or satellite cell nuclei (Koishi et al. 1995; Dupont-Versteegden et al. 1998; Cooper et al. 1999). Cooper et al. (1999) are the only ones who have applied a method of direct identification of satellite cells by using an antibody against M-cadherin, which is known as a definitive marker of quiescent and activated satellite cells (for reviews, see Kaufmann et al. 1999; Hawke and Garry 2001).

Aging-associated alterations are now understood to represent a complex network of events that might change skeletal muscle homeostasis at both cellular and molecular levels (for reviews, see Larsson and Ramamurthy 2000; Navarro et al. 2001). The absence of appropriate innervation in some muscle fibers and the activation of quiescent satellite cells are thought to constitute a significant part of this change (for reviews, see Larsson 1982; Carlson 1995; Faulkner et al. 1995). However, uncertainty continues to exist regarding the question of whether muscle fiber denervation and/or satellite cell activation is the possible cause of the altered MyoD and myogenin expression in senile muscles. In the past few years, only Musaro et al. (1995) and Kostrominova et al. (2000) have shown myogenin protein accumulation in the nuclei of old skeletal muscle fibers. No attempts have been made to determine whether satellite cells also contribute to the increased myogenin protein expression in these studies. Moreover, the cellular source of MyoD protein expression in old skeletal muscle remains as yet unspecified.

The present study has been specially designed to analyze the level of MyoD and myogenin protein expression in skeletal muscle of aged and, in particular, of senile (32-month-old) WI/HicksCar rats and to specify the cellular origin of the production of these MRFs. In addition, we have attempted to obtain results that would explain the possible causes of the altered levels of expression of MyoD and myogenin proteins in 32-monthold skeletal muscles. Our study has demonstrated a marked increase of MyoD and myogenin protein expression in the muscles of senile rats. The up-regulation of these MRF proteins is associated with their accumulation in the nuclei of a majority of NCAM positive (NCAM+) myofibers and in the nuclei of a small number of $\mathrm{M}$ cadherin positive (M-cad+) satellite cells. Furthermore, based on our observations, we suggest that complete or partial denervation of fibers and compensatory activation of M-cad+ satellite cells associated with presumably denervated (or recently re-innervated) fibers might constitute the most likely causes of the elevated level of MRF expression in the hindlimb skeletal muscles of senile WI/ HicksCar rats.

\section{Materials and methods}

Animals and materials

This study was conducted on male WI/HicksCar rats of various ages (Table 1). During the aging process, rats were maintained under pathogen-free conditions at Harlan-Sprague-Dawley (Indianapolis). Survival and pathology data on aging WI/HicksCar rats have been previously published (Carlson et al. 2001). At the University of Michigan, all manipulations and animal care were carried out in accordance with the guidelines of the Unit for Laboratory Animal Medicine. Muscle excision and subsequent euthanasia of the animals were performed under ether anesthesia. The gastrocnemius, tibialis anterior (TA), and extensor digitorum longus (EDL) muscles were harvested and used for Western blotting, immunohistochemistry, and electron microscopy. In addition, gastrocnemius muscles that had been denervated for 21 days by sciatic nerve transection (dG) and TA and EDL muscles that had undergone regeneration for 4 days after $0.75 \%$ bupivacaine

Table 1 Animals and muscles used in the experiments $(G$ gastrocnemius muscle, $T A$ tibialis anterior muscle, $E D L$ extensor digitorum longus muscle, $d G$ 4-month-old gastrocnemius muscles denervated for 21 days by sciatic nerve transection, rTA 4-monthold TA muscle regenerated for 4 days after Marcaine injection, $r E D L$ 4-month-old EDL muscle regenerated for 4 days after Marcaine injection)

\begin{tabular}{|c|c|c|}
\hline $\begin{array}{l}\text { Age group } \\
\text { of rats }\end{array}$ & $\begin{array}{l}\text { Age } \\
\text { (number of rats) }\end{array}$ & $\begin{array}{l}\text { Type of muscle } \\
\text { (number of muscles) }\end{array}$ \\
\hline Young adult & 4 months (8) & $\begin{array}{l}\text { G (8) } \\
\text { TA (3) } \\
\text { EDL (3) } \\
\text { dG (3) } \\
\text { rTA (3) } \\
\text { rEDL (3) }\end{array}$ \\
\hline Old & $\begin{array}{l}24 \text { months (3)- } \\
26 \text { months (3)- } \\
28 \text { months (3) }\end{array}$ & $\begin{array}{l}\text { G (6) } \\
\text { EDL (3) } \\
\text { G (6) } \\
\text { EDL (3) } \\
\text { G (6) }\end{array}$ \\
\hline Senile & 32 months (4)- & $\begin{array}{l}\mathrm{G}(8) \\
\operatorname{EDL}(4)\end{array}$ \\
\hline
\end{tabular}


hydrochloride (Marcaine, Winthrop, N.Y.) injection (rTA and rEDL) were also collected from young adult rats (Table 1). The muscles, which were analyzed by more than one method, were cut into equal halves that were processed according to the particular protocol.

Light and transmission electron microscopy

The muscles were dissected into small pieces and fixed with a mixture of $2.5 \%$ formaldehyde and $2.5 \%$ glutaraldehyde in $0.1 \mathrm{M}$ sodium cacodylate buffer, $\mathrm{pH} 7.4$ (Electron Microscopy Sciences, Fort Washington, Pa.) for $5 \mathrm{~h}$ at $4^{\circ} \mathrm{C}$. The samples were washed in $0.25 \mathrm{M}$ sucrose and then post-fixed in $1 \% \mathrm{OsO}_{4}$ for $1 \mathrm{~h}$ at $4^{\circ} \mathrm{C}$. The muscle pieces were dehydrated in a graded series of ethanol and absolute acetone at room temperature (RT) and were embedded in a mixture of Epon/Araldite by using an Eponate 12-Araldite $502 \mathrm{Kit}$ (Ted Pella, Redding, Calif.). Semi-thin $(1.0 \mu \mathrm{m})$ and ultra-thin $(75-$ $85 \mathrm{~nm})$ sections were cut on an ultramicrotome. The $1.0-\mu \mathrm{m}$ sections were mounted on glass slides and stained with toluidine blue for general observation. Ultra-thin sections were collected on Formvar-coated slotted grids and stained with uranyl acetate and lead citrate. Observation and photography of the sections were made with a Philips CM-100 transmission electron microscope.

Immunohistochemistry and immunofluorescence microscopy

Pieces of muscle were fixed in freshly prepared $2 \%$ paraformaldehyde in $0.1 \mathrm{M}$ phosphate-buffered saline (PBS) for $24 \mathrm{~h}$ at $4^{\circ} \mathrm{C}$. The samples were washed overnight in PBS, cryo-protected in a graded sucrose series, placed in specimen molds containing TBS/ Tissue Freezing Medium (Triangle Biomedical Sciences, Durham, N.C.), and then frozen by immersing the molds in isopentane that had been pre-cooled by dry ice. Transverse and longitudinal $9.0-\mu \mathrm{m}$ serial sections were cut on a cryostat at $28^{\circ} \mathrm{C}$ and mounted on glass slides. Before staining, the sections were fixed in $100 \%$ methanol at $20^{\circ} \mathrm{C}$ for $10 \mathrm{~min}$. The slides were allowed to air-dry, and then the sections were re-hydrated in PBS and incubated with $10 \%$ normal goat serum for $20 \mathrm{~min}$ at RT. Labeling with mixtures of primary antibodies (Table 2) was carried out for $3 \mathrm{~h}$ at $37^{\circ} \mathrm{C}$. After incubation, the sections were washed in PBS, incubated with $10 \%$ normal goat serum for $10 \mathrm{~min}$, and stained with a mixture of secondary antibodies for $45 \mathrm{~min}$ at RT. Fluorescein isothiocyanate (FITC)- and Cy3-conjugated goat anti-mouse and goat anti-rabbit secondary antibodies (Jackson ImmunoResearch Laboratories, West Grove, Pa.) were used for visualization of primary antibodies. As controls, omissions and substitution of one or both primary antibodies by normal goat serum were used. To indicate the area of the postsynaptic membrane in a neuromuscular junction an $\alpha$ bungarotoxin tetramethylrhodamine conjugate (Molecular Probes, Eugene, Ore.) was utilized during incubation with the secondary antibody. After staining, the sections were rinsed in PBS, mounted in Vectashield mounting medium for fluorescence with 4,6diamidino-2-phenylindole (DAPI; Vector Laboratories, Burlingame, Calif.) to counterstain nuclei, and cover-slipped. Observation and photography of the sections were made with a Zeiss Axiophot2 Universal Microscope (Carl Zeiss, Germany) equipped with Cy3, FITC, and UV filters and with differential interference contrast optics (DIC). Photomicrographs printed from film were scanned into a computer; fluorescence and DIC images were directly captured by using a Zeiss Axiocam digital camera. Figures were prepared from electronic images by using Adobe Photoshop software (Adobe Systems, San Jose, Calif.).

\section{Western blot analysis}

Muscles frozen in liquid nitrogen were homogenized in a solution containing $20 \mathrm{mM}$ TRIS-HCl (pH 6.8), 4\% sodium dodecyl sulfate (wt/vol), $1 \mathrm{mM}$ phenylmethylsulfonyl fluoride, and $1 \mu \mathrm{M}$ each of leupeptin and pepstatin A. The homogenates were centrifuged at $4^{\circ} \mathrm{C}$ for $10 \mathrm{~min}$ at $5000 \mathrm{~g}$, and the supernatants were collected. The protein concentration in each sample was measured with a spectrophotometer by using the Bio-Rad detergent-compatible protein assay (Hercules, Calif.). An equal amount of protein from each sample was mixed with loading buffer (50 $\mu \mathrm{g} / \mathrm{lane})$, run on $10 \%$ sodium dodecyl sulfate-polyacrylamide gels under reducing conditions, and than transferred onto Immobilon-P membranes (Millipore, Bedford, Mass.). The recombinant MyoD and myogenin proteins (SC-4080 and SC-4081, respectively; Santa Cruz Biotechnology, Santa Cruz, Calif.) were diluted with loading buffer (60 ng/ lane) and used as a control of antibody specificity. Gels with similar samples were stained with Coomassie brilliant blue and used as a control of protein loading. After transfer, the Immobilon-P membranes were blocked in buffer containing 5\% dry milk in PBS- $0.05 \%$ Tween 20 and then incubated overnight at $4{ }^{\circ} \mathrm{C}$ with primary antibodies. In preliminary experiments, four different antiMyoD specific antibodies were initially tested for use in Western blotting: polyclonal rabbit anti-MyoD C-20 and M-318 (SC-304 and SC-760, respectively; Santa Cruz Biotechnology) and monoclonal mouse anti-MyoD1, clone 5.8A and clone 5.2F (MS-273-P and MS-278-P, respectively; NeoMarkers, Fremont, Calif.). Polyclonal rabbit anti-MyoD C-20 (1:200; SC-304; Santa Cruz Biotechnology) and monoclonal mouse anti-myogenin, clone F5D (1:5; Developmental Studies Hybridoma Bank, The University of Iowa, Iowa City, Iowa) antibodies were only used in the complete immunoblotting study. In addition, samples of muscle extract identical to those that were used for the detection of the levels of MyoD and myogenin proteins were employed for Western blotting with a mouse anti- $\alpha$-sarcomeric actin antibody (1:100; A2172; Sigma, St. Louis, Mo.). In order to confirm the specificity of the bands with MyoD-like immunoreactivity, an extract from senile gastrocnemius muscle $(50 \mu \mathrm{g} / \mathrm{lane})$ and a diluted recombinant MyoD protein $(10 \mathrm{ng} / \mathrm{lane})$ were used for immunoblotting with a polyclonal anti-MyoD antibody that was pre-incubated with a 5fold excess of recombinant MyoD protein as described by the manufacturer (Santa Cruz Biotechnology). Immunodetection was performed by means of peroxidase-conjugated goat anti-mouse or anti-rabbit antibodies (Jackson ImmunoResearch Laboratories), respectively, with subsequent chemiluminescence (ECL, Amersham Pharmacia Biotech, Piscataway, N.J.). Each blot was scanned

Table 2 Primary antibodies used for immunostaining (DSHB Developmental Studies Hybridoma Bank)

\begin{tabular}{lllll}
\hline Antigen & Clone & Dilution & Catalog number & Source \\
\hline MyoD1 & 5.8A & $1: 50$ & MS-273-P & NeoMarkers, Union City, Calif. \\
Myogenin & F5D & Supernatant & F5D & DSHB, University of Iowa, Iowa City, Iowa \\
Laminin B2 & D18 & Supernatant & D18 & DSHB \\
Fast/neonatal myosin & N3.36 & Supernatant & N3.36 & DSHB \\
Slow muscle myosin & NOQ7.5.4D & $1: 70$ & MAB1628 & Chemicon International, Temecula, Calif. \\
Synaptophysin & SVP-38 & $1: 100$ & MAB368 & Chemicon International \\
NCAM & Polyclonal & $2 \mu \mathrm{g} / \mathrm{ml}$ & AB5032 & Chemicon International \\
Laminin & Polyclonal & $1: 30$ & L9393 & Sigma, St. Louis, Mo. \\
M-cadherin & Polyclonal & $1: 50$ & Gift & A. Wernig, University of Bonn, Germany \\
S100 & Polyclonal & $1: 200$ & Z0311 & DAKO, Carpinteria, Calif.
\end{tabular}


into a computer, and images were stored in TIFF format. The intensity of the bands of MyoD and myogenin proteins was quantified by using NIH Image software. The protein level in senescent muscles was expressed relative to the protein level of young adult muscle that served as a control.

Quantitative analysis

Images from randomly selected areas of cross-sectioned EDL muscles from 32-month-old rats were captured under the same magnification with a Zeiss Axiophot-2 universal microscope by using a Zeiss Axiocam digital camera. In each case, a few discrete images of the same examined areas were recorded by using the proper filter for fluorescence (FITC, Cy3, and UV for DAPI) and DIC. The following combinations of images were taken: (1) the fiber basal lamina positive for laminin (FITC), M-cad+ satellite cells (Cy3), nuclei (DAPI); (2) M-cad+ satellite cells (FITC), MyoD+ satellite cells (Cy3), nuclei (DAPI), myofiber profiles (DIC); (3) M-cad+ satellite cells (FITC), myogenin+ satellite cells (Cy3), nuclei (DAPI), myofiber profiles (DIC); and (4) the fiber basal lamina positive for laminin (FITC), NCAM+ fibers (Cy3). The separate electronic images of the same microscopic field were transformed into a single composite figure by using Adobe Photoshop (Adobe Systems, San Jose, Calif.). The numbers of muscle fiber profiles outlined with either the laminin-positive basal lamina or DIC were calculated on figures from each entirely crosssectioned EDL muscle. In total, 2500 muscle fiber profiles were collected for each muscle. The numbers of M-cad+ satellite cells and NCAM+ fibers were expressed as percentages of the total number of fibers examined. The numbers of M-cad+/MyoD+ and $\mathrm{M}$-cad+/myogenin+ satellite cells were expressed as percentages of the total number of M-cad+ satellite cells associated with the total number of fibers examined.

Statistics

Data were analyzed by a two-factor analysis of variance followed by the Student $t$ test (unpaired sample). The values were expressed as means \pm SEM. The significance of differences in protein levels measured in old and senile skeletal muscles was set at $P \leq 0.05$.

\section{Results}

Level of MyoD and myogenin protein expression in aged skeletal muscles

Western blotting showed that, compared with young adult animals, the levels of myogenin protein were $\sim 3.2, \sim 4.0$, and $~ 5.5$ times higher in gastrocnemius muscles of 24-, 26-, and 32-month-old rats, respectively (Figs. 1, 2). At the same time, whereas immunoblotting of the muscle extracts from young adult rats with an antibody against MyoD detected immunoreactivity with molecular weight 43-45 kDa (a single band), immunoblotting of the muscle extracts from aged rats with the same antibody demonstrated the immunoreactivity in two major areas, with molecular weight $\sim 43-45 \mathrm{kDa}$ and $\sim 55-65 \mathrm{kDa}$ (the double or triple band; Fig. 3). To confirm the specificity of MyoD-like immunoreactivity (55-65 kDa) seen in muscle extracts from senile rats, the antibody against MyoD was pre-incubated with a recombinant MyoD protein. This pre-incubation drastically reduced the ability of the polyclonal rabbit anti-MyoD C-20 antibody to
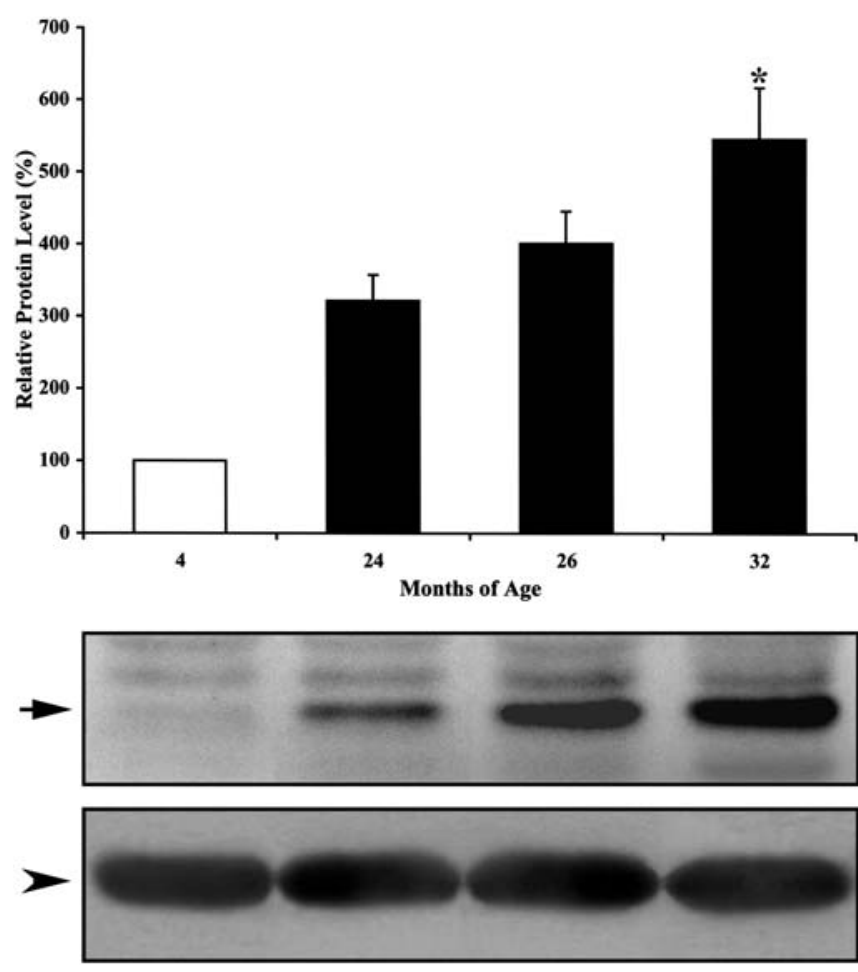

Fig. 1 Histogram (top values: mean \pm SEM) and representative Western blots (bottom) showing relative levels of myogenin expression in gastrocnemius muscles from senescent rats (arrow myogenin-specific band with molecular weight $\sim 32-34 \mathrm{kDa}$, arrowhead band with molecular weight $\sim 45 \mathrm{kDa}$ specific for $\alpha$ sarcomeric actin in Western blots with the same muscle extracts). Note that the level of myogenin protein expression increases with aging, whereas the level of $\alpha$-sarcomeric actin remains similar (top, asterisk myogenin protein expression in muscles of 24- and 32month-old rats demonstrate a significant difference at $P \leq 0.05$ )

detect both MyoD-specific (43-45 kDa) and MyoD-like (55-65 kDa) bands (Fig. 2). The level of MyoD protein in the $43-$ to $45-\mathrm{kDa}$ band remained relatively unchanged during aging. At the same time, the total level of MyoDlike immunoreactivity in the $55-$ to $65-\mathrm{kDa}$ bands was $\sim 3.4, \sim 4.7, \sim 9.1$, and $\sim 11.7$ times higher in gastrocnemius muscles of 24-, 26-, 28-, and 32-month-old rats, respectively, compared with 4-month-old animals (Fig. 3).

Because MyoD immunoreactivity was recognized in the $43-$ to $45-\mathrm{kDa}$ and $55-$ to $65-\mathrm{kDa}$ bands in the gastrocnemius muscle of senile rats, analyses of gastrocnemius, EDL, and TA muscles from young adult rats were made. This was carried out in order to determine whether the appearance of the upper bands was an exclusive characteristic of the gastrocnemius muscle or a more general feature of aged and, in particular, senile rats. The extracts from 4-month-old TA, EDL, and gastrocnemius muscles demonstrated presence of the prominent 43- to $45-\mathrm{kDa}$ band, whereas 55- to $65-\mathrm{kDa}$ bands were only faintly detectable (Fig. 4, lanes: 4mTA, 4mEDL, and $4 \mathrm{mG}$ ). According to these results, the presence of the 43to $45-\mathrm{kDa}$ band was a characteristic of skeletal muscles from both aged and young adult rats, whereas the 


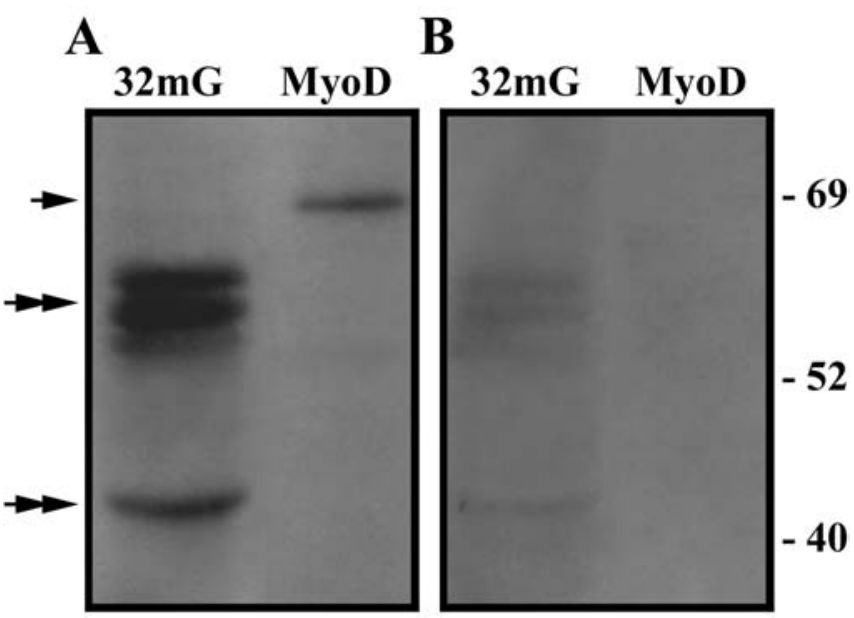

Fig. 2A, B Western blotting of a 32-month-old gastrocnemius muscle $(32 m G)$ and a recombinant MyoD protein $(M y o D)$ with a polyclonal antibody against MyoD (arrow band specific for a recombinant MyoD protein, double arrows 43- to 45-kDa MyoDspecific and $\sim 55-$ to $65-\mathrm{kDa}$ MyoD-like bands) in representative Western blots. A Without pre-incubation with a recombinant MyoD protein. B With pre-incubation with a recombinant MyoD protein. Note that pre-incubation of the polyclonal rabbit anti-MyoD C-20 antibody with a recombinant MyoD protein $(M y o D)$ drastically diminishes the immunoreactivity of both bands in the muscle extract

prominence of the 55- to $65-\mathrm{kDa}$ bands was a distinctive feature of skeletal muscle from aged and, in particular, senile animals.

The values of both myogenin and MyoD protein expression demonstrated a significant degree of difference between skeletal muscles of 24- and 32-month-old rats (Figs. 1, 3A). Despite the finding that myogenin and MyoD protein production reached a higher level in 24month-old muscles than in the muscles of 4-month-old rats, the skeletal muscles of 32-month-old animals showed a further elevation of expressions of both MRF proteins.

Comparison of the pattern of MyoD and myogenin protein expression in senile muscle with that in denervated and regenerating muscles from young adult rats

Because MyoD and myogenin expression attained the highest levels in the muscles of 32-month-old rats, we hypothesized that this event was a result of either fiber denervation or activation of satellite cells. In order to confirm this hypothesis, the expression pattern of MRF proteins recorded in senile muscles was compared with that in muscles of 4-month-old rats subjected to two different experimental approaches: post-injury regeneration and acute motor denervation. In the first approach, TA and EDL muscles of young adult rats were injected with a myotoxic agent (bupivacaine). This treatment resulted in the death of fibers and activation of a
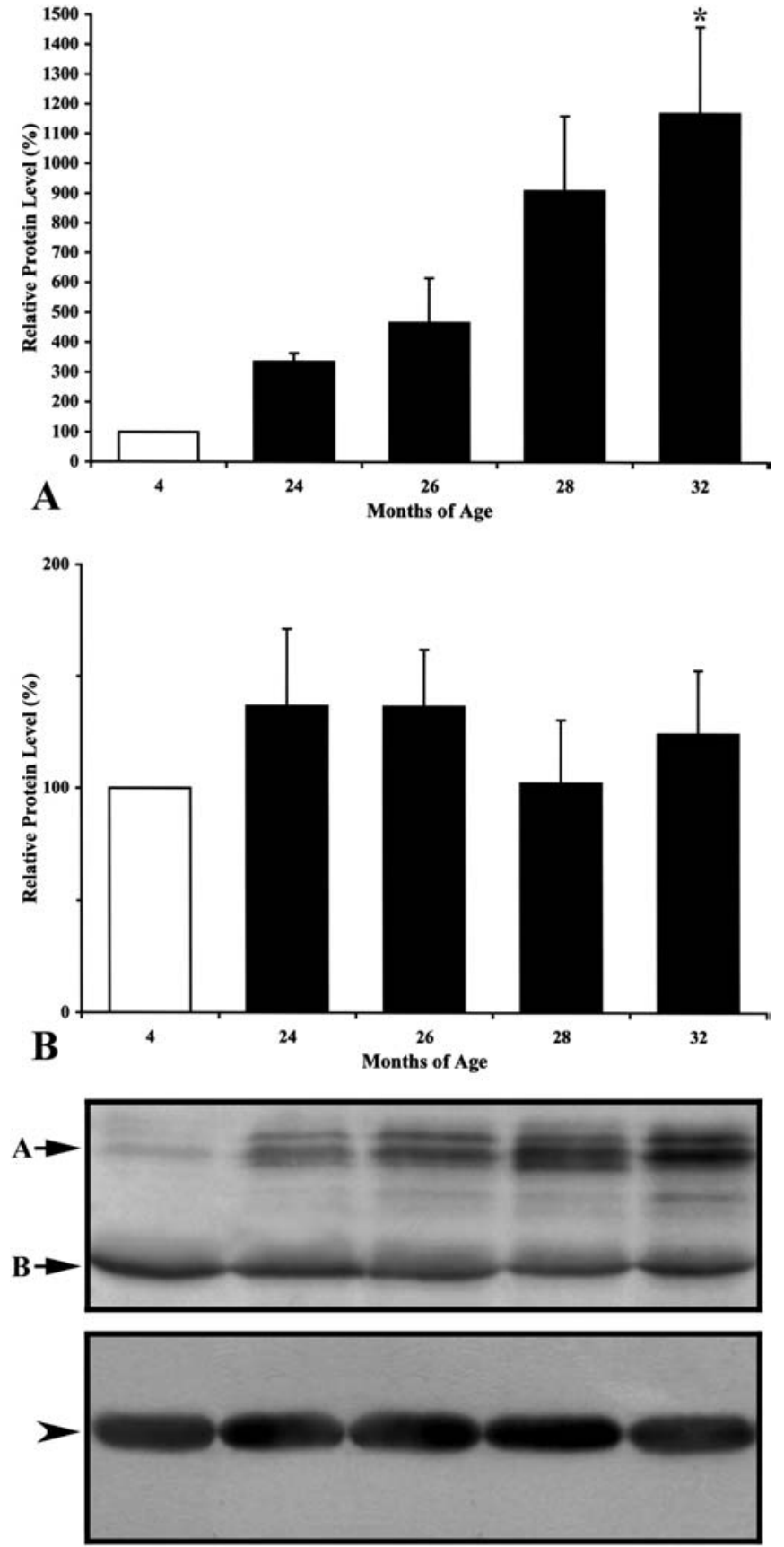

Fig. 3 Top A, B Relative levels of MyoD protein expression in gastrocnemius muscles from aged rats (values are mean \pm SEM). Bottom Representative Western blot (arrow A duplet or triplet bands of MyoD-like immunoreactivity with molecular weight $~ 55$ $65 \mathrm{kDa}$ related to $\mathbf{A}$, arrow $B$ single band of MyoD-specific protein with molecular weight $\sim 43-45 \mathrm{kDa}$ related to $\mathbf{B}$, arrowhead a band with molecular weight $\sim 45-\mathrm{kDa}$ specific for $\alpha$-sarcomeric actin in Western blots with the same muscle extracts, asterisk value of MyoD protein expression with a significant degree of difference between muscles of 24- and 32-month-old rats at $P \leq 0.05$ ). Note that, whereas the level of MyoD-like immunoreactivity that is recognized as the 55- to $65-\mathrm{kDa}$ bands $(\mathbf{A})$, steadily increases with aging, the level of MyoD protein in the 43- to 45-kDa band (B) and the level of $\alpha$-sarcomeric actin remain relatively unchanged among aged rats 


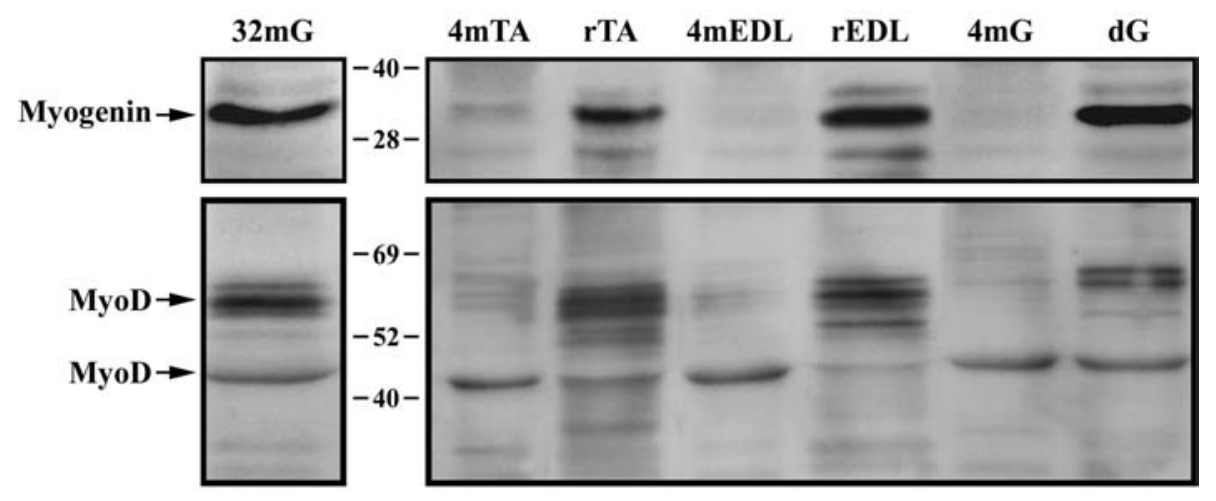

Fig. 4 Representative Western blots showing the expression of myogenin and MyoD proteins in gastrocnemius $(\mathrm{G})$, tibialis anterior (TA), and extensor digitorum longus (EDL) muscles from senile (32-month-old) and young adult (4-month-old) rats $(32 m G$ 32-month-old gastrocnemius muscle, 4mTA 4-month-old TA muscle, rTA 4-month-old TA muscle regenerated for 4 days after Marcaine injection, 4mEDL 4-month-old EDL muscle, $r E D L$ 4month-old EDL muscle regenerated for 4 days after Marcaine injection, $4 m G$ 4-month-old gastrocnemius muscle, $d G$ 4-monthold gastrocnemius muscles denervated for 21 days by sciatic nerve transection). Note that a myogenin-specific band (Myogenin, arrow) with molecular weight $\sim 32-34 \mathrm{kDa}$ is detected in senile and young adult regenerating and denervated skeletal muscles, whereas in normal skeletal muscles from young adult rats, there is practically no detectable myogenin expression. The presence of the MyoD-like bands (MyoD, arrows) with molecular weight $~ 55$ $65 \mathrm{kDa}$ is a prominent feature of senile muscle and regenerating and denervated muscles of young adult rats. In contrast to senile and young adult denervated muscle, the 43- to 45-kDa MyoDspecific band is significantly diminished in the regenerating muscle remarkable number of satellite cells. In the second approach, the gastrocnemius muscle of young adult rats was denervated by transection of the sciatic nerve. This procedure instantly triggered an intense compensatory response in the majority of existing (living) fibers and, to a lesser degree, stimulated the activation of a small number of satellite cells.

Immunoblotting with an anti-MyoD antibody demonstrated an increase in abundance of the $\sim 55-$ to $65-\mathrm{kDa}$ bands in extracts of both regenerating and denervated young adult skeletal muscles (Fig. 4, lanes: rTA, rEDL, dG) compared with control muscles. The intensity of the 43- to 45-kDa band in regenerating muscles was markedly decreased, whereas in denervated muscles, it remained practically unchanged compared with that of intact skeletal muscles. Thus, the pattern of MyoD protein expression in 32-month-old gastrocnemius muscles (Fig. 4, lane 32mG) is reminiscent of that detected in denervated muscles of 4-month-old rats.

Analogous to MyoD, immunoblotting with an antimyogenin antibody showed that the pattern of protein expression in 32-month-old muscle is similar to that of denervated muscles from 4-month-old rats (Fig. 4, lanes: $32 \mathrm{mG}$ and dG). However, in contrast to MyoD, these data displayed a high degree of similarity between the patterns of expression seen in senile and 4-month-old regenerating muscles (Fig. 4, lanes: 32mG, rTA, and rEDL).

In summary, the patterns of MyoD and myogenin expression in 32-month-old skeletal muscle are highly comparable with those in denervated young adult muscles and, to a lesser degree, in regenerating muscles of 4month-old rats.

\section{Ultrastructural examination of senile skeletal muscle}

The ultrastructural analysis of 32-month-old EDL muscle was performed to verify the possible presence of denervated muscle fibers and activated satellite cells. The presence of degenerative alterations in the area of some neuromuscular junctions was found. In such cases, neuromuscular junctions were partially or completely devoid of motor axon terminals (Fig. 5A, B). At the same time, satellite cells with structural features characteristic of activated cells were also observed (Fig. 5C, D). On rare occasions, manifestations of compensatory myogenesis occurring on the surface of living muscle fibers were detected in senile EDL muscles (Figs. 5D, 6). These findings demonstrated that the processes related to muscle fiber denervation and to the activation of satellite cells were indeed present in skeletal muscle of 32-month-old rats.

Determination of the source of MyoD and myogenin protein expression in senile muscle

The patterns of expression of both MRF proteins were examined in senile EDL muscles by immunohistochemistry to confirm the hypothesis that denervated fibers and/ or activated satellite cells were the sources of MyoD and/ or myogenin production. Intact 4-month-old EDL muscles were used as a negative control, whereas regenerating and denervated muscles from the same rats served as a positive control. Immunostaining of 4-month-old intact EDL muscles demonstrated no detectable expression of MRF proteins, whereas nuclei stained positively for MyoD and myogenin were seen in regenerating and in denervated young adult muscles (data not shown). 

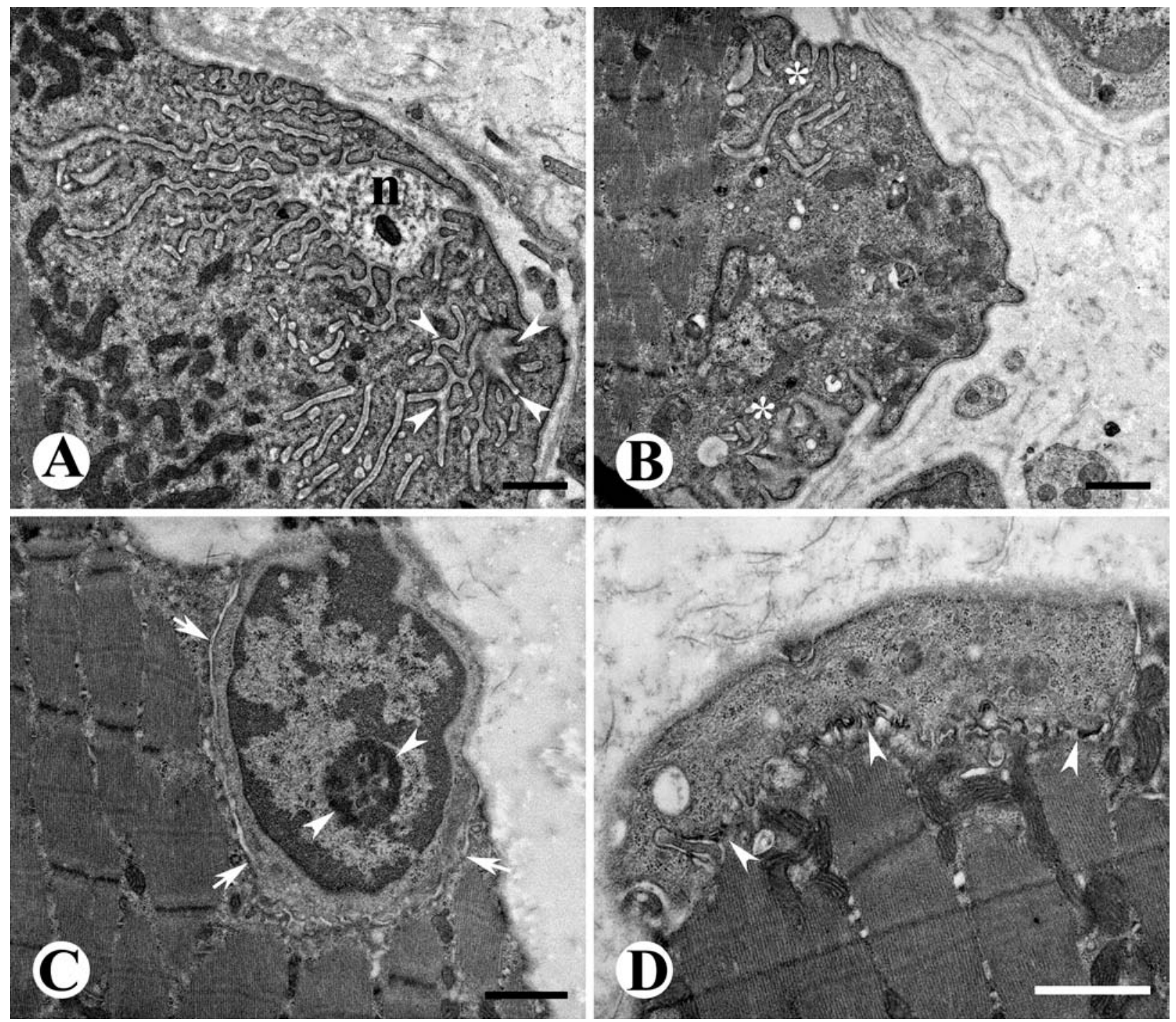

Fig. 5A-D Electron micrographs showing degenerative alterations in the area of neuromuscular junctions and structural features characteristic of activated satellite cells in 32-month-old EDL muscles. A Neuromuscular junction partially devoid of axon terminals ( $n$ nerve terminal). Note the area from which an axon terminal has withdrawn (arrowheads). B Neuromuscular junction completely devoid of axon terminals. Note areas where axon terminals have withdrawn (asterisks). C Activated satellite cell

Immunostaining of cross sections from EDL muscles of 32-month-old rats demonstrated that MyoD and myogenin proteins accumulated in the myonuclei of some fibers (Figs. 7, 8). Examination of adjacent serial cross sections showed that both MRF proteins could be concurrently expressed in the same muscle fiber (Fig. 7) or even in the same myonucleus (Fig. 8). Moreover, in a majority of cases, MyoD+ and myogenin+ fibers occupied only part of the muscle fascicles, but, occasionally, an entire fascicle consisted of such fibers. About $17 \%$ of all examined fibers from 32-month-old EDL muscles were estimated as expressing MRF proteins.

(arrows) located in a groove-like channel on the surface of a muscle fiber. Note the developed nucleolus inside the satellite cell nucleus (arrowheads). D Activated satellite cell showing cytoplasm containing microfilaments and abundant ribosomes. Note that membrane/cytoplasmic extensions from both satellite cell and muscle fiber interdigitate within the intracellular cleft (arrowheads) and sometimes fuse together. Bars $1 \mu \mathrm{m}$

In order to verify the expression of MyoD and myogenin proteins in the nuclei of satellite cells from senile EDL muscle, combined immunostaining with antibodies against M-cadherin, as a specific marker of myogenic cells, and either MyoD or myogenin was used. In addition, the numbers of M-cad+, M-cad+/MyoD+, and M-cad+/myogenin+ satellite cells were calculated in 32month-old EDL muscles. Immunostaining of cross sections of a control 4-month-old EDL muscle showed that the occasional M-cad+ satellite cells remained negative for MyoD and myogenin (data not shown). On the other hand, immunostaining of cross sections of 32-month-old EDL muscles demonstrated that either MyoD or myo- 


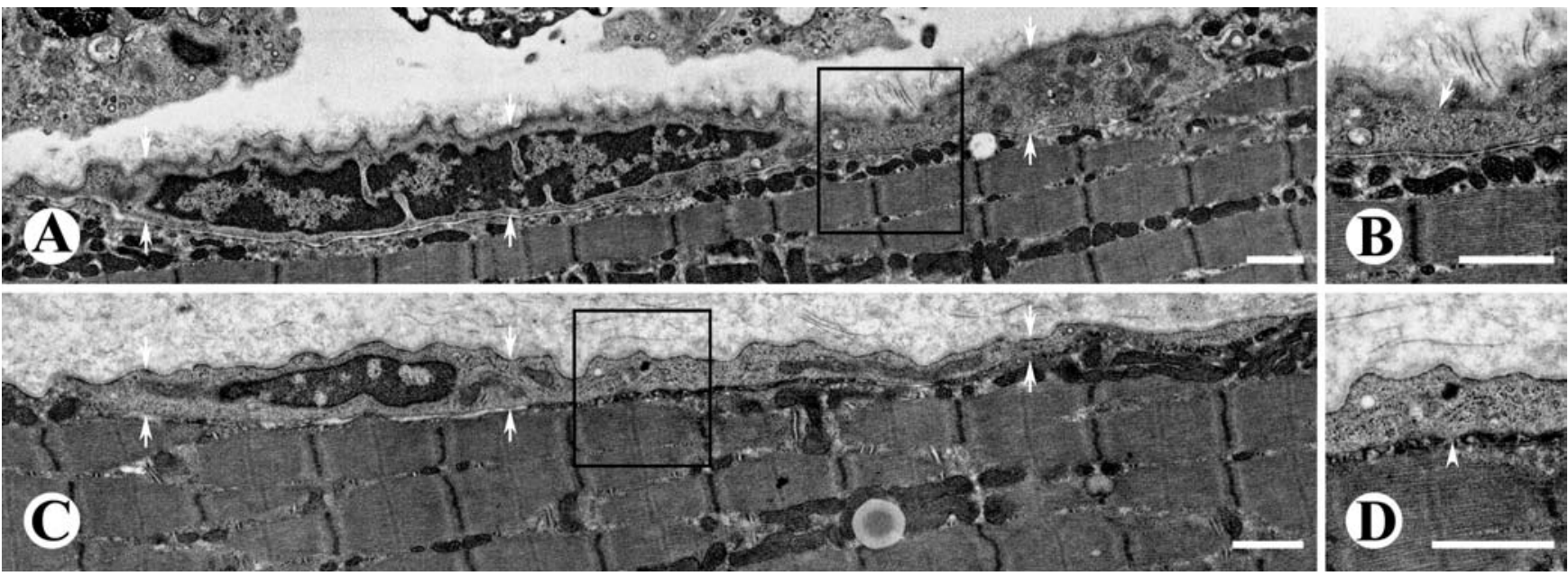

Fig. 6A-D Electron micrographs displaying structural manifestations of compensatory myogenesis on the surface of living muscle fibers from 32-month-old EDL muscles. A, C Two activated satellite cells (arrows) resting on the surface of living muscle fibers are stretched out along the longitudinal axis of the fibers. Both cells demonstrate markedly developed cytoplasmic extensions. B, D Higher magnification of the areas outlined in $\mathbf{A}$ and $\mathbf{C}$, respectively,

genin accumulates in nuclei of M-cad+ satellite cells (Fig. 9). Because cells that possessed characteristics of myoblasts were never seen at the level of the electron microscopy in muscles of 32-month-old rats, we decided to term M-cad+/MyoD+ and M-cad+/myogenin+ cells as activated satellite cells. These satellite cells often displayed features indicating their activated status, such as extensions of cytoplasm (Fig. 9D-F) and membrane contacts between adjacent cells (Fig. 9G-I). It was estimated that the number of M-cad+ satellite cells in 32 -month-old EDL muscles was about $12.9 \pm 4.1 \%$ of the total number of examined fibers. At the same time, the frequency of $\mathrm{M}$-cad+/MyoD+ and M-cad+/myogenin+ cells was $\sim 3.8 \pm 0.3 \%$ and $\sim 3.2 \pm 0.5 \%$, respectively, of the total number of M-cad+ satellite cells, or $\sim 0.5 \pm 0.2 \%$ and $\sim 0.4 \pm 0.2 \%$, respectively, of the total number of examined fibers.

These results show that both fibers and satellite cells indeed produce MyoD and myogenin in 32-month-old skeletal muscles. However, the overall expression of both MRF proteins seems to be markedly greater in fibers than that in activated satellite cells.

Description of the potential profile of MyoD+ and myogenin+ muscle fibers and satellite cells in senile skeletal muscle

Muscle fiber innervation was analyzed in senile EDL muscles by immunohistochemistry to verify the hypothesis that denervated fibers and/or associated satellite cells might be the sources of MyoD and/or myogenin production. A well-known molecular marker indicative of the disruption of motor innervation in muscle fibers is the showing the presence, in activated satellite cells, of numerous micropinocytotic vesicles mainly under the external cytolemma (B) and cytoplasm with abundant ribosomes and rough endoplasmic reticulum. Note that, in $\mathbf{D}$, membrane materials fill the cleft between the activated satellite cell and the muscle fiber. Fusion is also seen between the cytoplasm of the satellite cell and the associated fiber (arrowhead). Bars $1 \mu \mathrm{m}$

neural cell adhesion molecule (NCAM). Immunostaining of sections of control EDL muscle from 4-month-old rats displayed no detectable NCAM expression (data not shown). At the same time, numerous NCAM+ fibers were seen in senile muscles (Fig. 10E). The expression of NCAM protein often exhibited a dispersed pattern throughout the cross sections of a single fascicle and a whole muscle. Moreover, NCAM expression was recorded in atrophic and in average size fibers. NCAM immunoreactivity was present in the plasmalemma and in the cytoplasm of fibers, and the intensity of NCAM expression varied markedly among fibers. It was estimated that the number of NCAM+ fibers in a 32-month-old EDL muscle was $\sim 17.3 \pm 5.3 \%$ of the number of all examined fibers.

To verify the possibility of the concurrent expression of NCAM and either MyoD or myogenin proteins in the same fibers, a co-staining technique was utilized. Immunostaining showed that the majority of NCAM+ fibers, regardless of labeling intensity, accumulated MyoD and/ or myogenin proteins in their myonuclei (Fig. 10A-D). Nevertheless, an accurate estimate of the numbers of either $\mathrm{NCAM}+\mathrm{MyoD}+$ or $\mathrm{NCAM}+/$ myogenin+ fibers was difficult because of the lack of myonuclei in some NCAM+ fiber profiles. Because NCAM-negative fibers only occasionally display the presence of MRF protein expression in myonuclei (data not shown), we suggest that $\mathrm{NCAM}+$ fibers are likely to be the major source of MyoD and myogenin protein production.

In order to check the presence or lack of axon terminals in the area of nerve-muscle junctions of $\mathrm{NCAM}+/ \mathrm{MyoD}+$ and $\mathrm{NCAM}+/$ myogenin+ fibers, antibodies against synaptophysin (a marker of motor nerve terminals) and S100 protein (a marker of Schwann cells) 

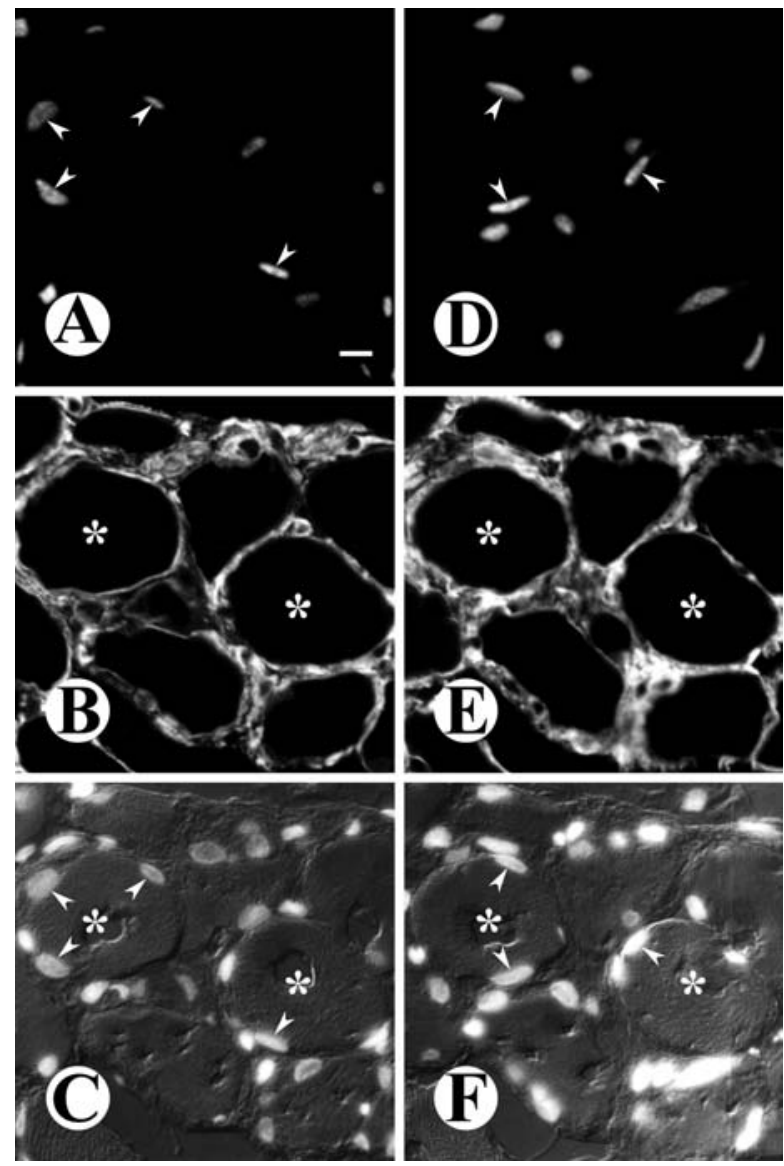

Fig. 7A-F Immunofluorescent photomicrographs of adjacent serial cross sections from a 32-month-old EDL muscle demonstrate the concurrent expression of $\mathrm{MyoD}$ and myogenin proteins within different nuclei of the same muscle fibers (asterisks). A MyoD+ myonuclei (arrowheads). B Laminin staining for A. C DIC image combined with nuclei staining with DAPI for A (arrowheads nuclei labeled positively for MyoD in A). D Myogenin+ myonuclei (arrowheads). E Laminin staining for D. F DIC image combined with nuclei staining DAPI for D (arrowheads nuclei labeled positively for myogenin in D). Bar $12.5 \mu \mathrm{m}$

in combination with $\alpha$-bungarotoxin labeling (a marker of acetylcholine receptors) were used. This staining was performed on adjacent serial cross sections of the same muscle area that had been previously examined for NCAM, MyoD, and myogenin protein expression (Fig. 10). Immunostaining confirmed that the NCAM, MyoD, and/or myogenin protein co-expression detected in fibers indeed coincided with partial (Fig. 11) or complete (Fig. 12) disruption of nerve terminals in the area of the nerve-muscle junction. At the same time, muscle fibers with intact motor innervation remained negative for the expression of NCAM and MRF proteins (data not shown). We suggest that the disruption of fiber innervation may be one of the causes of the increased expression of MyoD and myogenin proteins in the myonuclei of senile skeletal muscles of rats.

On the other hand, immunohistochemical examination of serial cross sections of 32-month-old EDL muscles
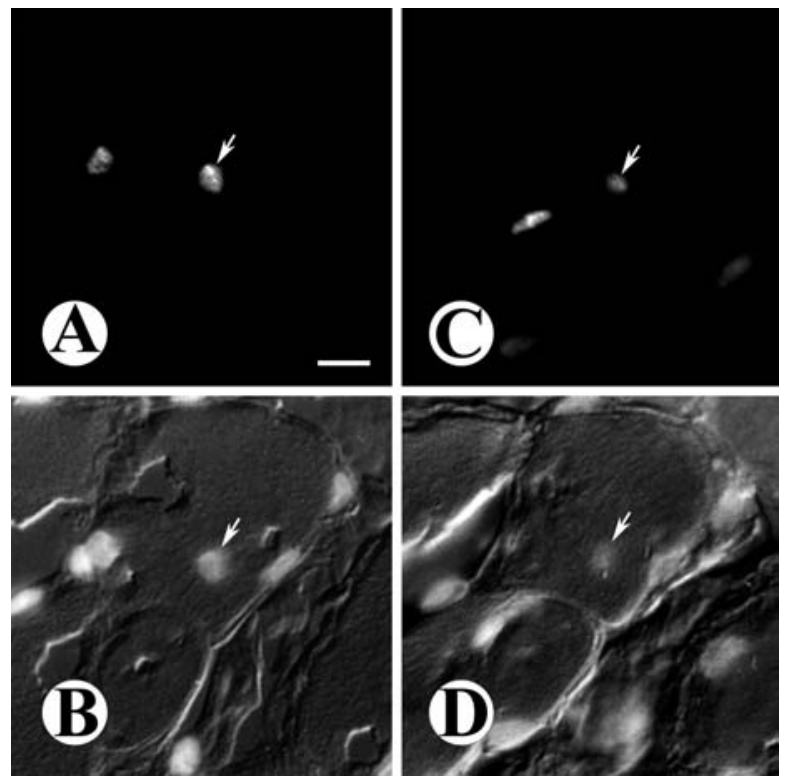

Fig. 8A-D Immunofluorescent photomicrographs of adjacent serial cross sections of 32-month-old EDL muscle showing the expression of both MyoD and myogenin in the same myonucleus of the same fiber. A MyoD+ myonucleus (arrow). B DIC image combined with nuclear staining with DAPI for $\mathbf{A}$ (arrow myonucleus labeled positively for MyoD in A). C The same myonucleus labeled positively for myogenin (arrow). A smaller profile of the myonucleus is a result of the nucleus in this section being cut closely to its apex. D DIC image combined with nuclear staining with DAPI for $\mathbf{C}$ (arrow indicates a myonucleus labeled positively for myogenin in C). Bar $12.5 \mu \mathrm{m}$

demonstrated that activated satellite cells with up-regulated expression of either MyoD or myogenin protein were associated with NCAM+, presumably nerve-deficient, fibers (Fig. 13). Occasionally, innervated muscle fibers that displayed no signs of atrophy and were negative for NCAM could also be seen in association with MRF+ satellite cells (Fig. 14). However, such myofibers also exhibited features of previous denervation/reinnervation incidents, including the co-expression of fast and slow types of myosin in the same fiber and the location of such a fiber in a fascicle showing fiber-type grouping (Fig. 14E, F). As activated MyoD+ and myogenin+ satellite cells are associated with fibers displaying present or past events of deficiency in motor innervation, we suggest that the participation of such satellite cells in compensatory myogenesis may be a possible reason for the increased expression of these MRF proteins in satellite cells from senile skeletal muscles of rats.

\section{Discussion}

This study has been designed to analyze levels of MyoD and myogenin proteins in skeletal muscles of senile rats and to specify the cellular source of production of these MRF. We have demonstrated that: (1) the level of MyoD and myogenin protein expression is markedly high in the 

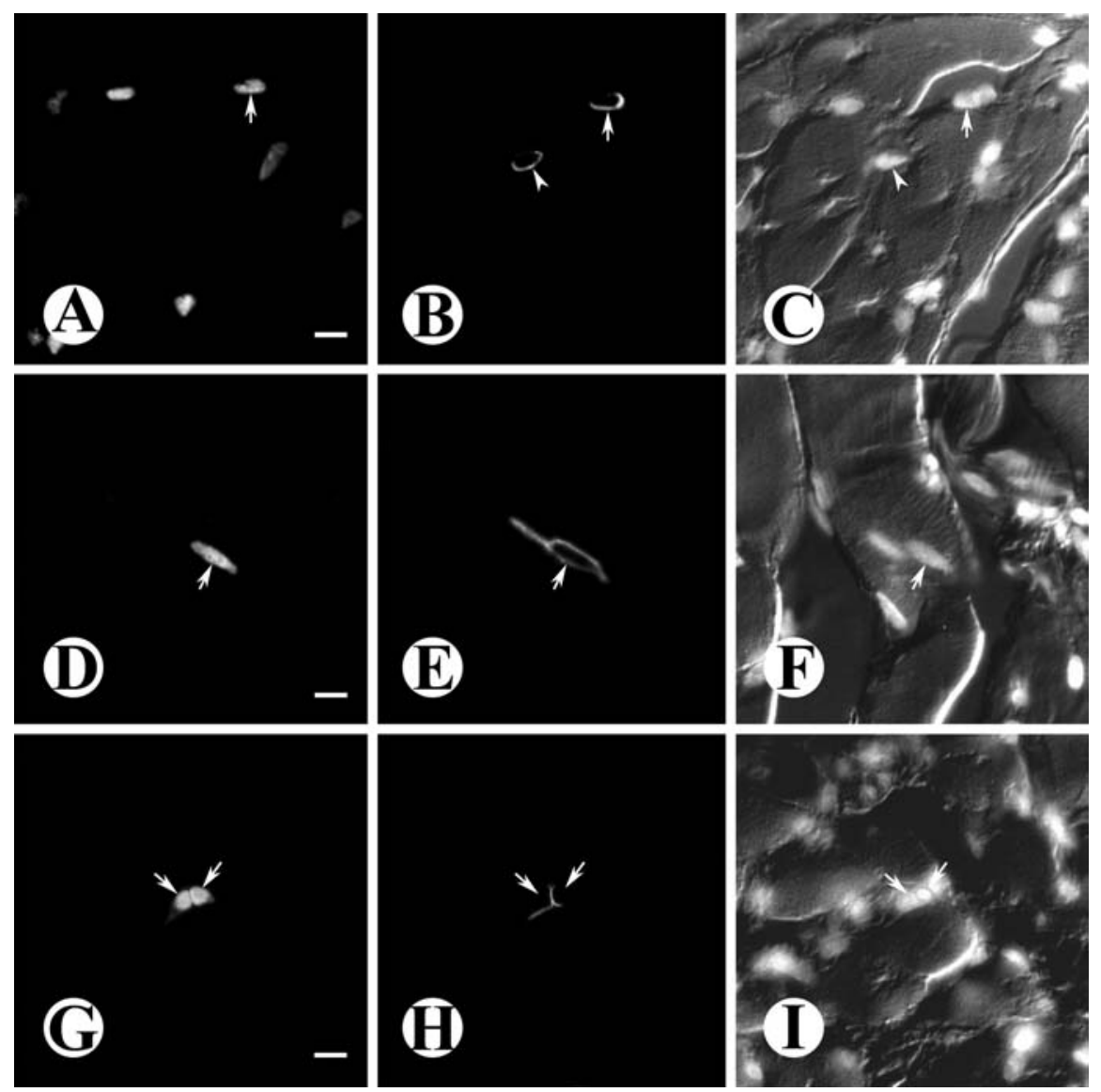

Fig. 9A-I Immunofluorescent photomicrographs demonstrating M-cadherin-positive satellite cells that express either MyoD or myogenin proteins located on the surface of living muscle fibers from the EDL muscle of a 32-month-old rat (arrows in D-F and GI the same satellite cells). A MyoD staining (arrow MyoD+ nucleus of a satellite cell). Note that a few MyoD+ myonuclei are also present. B M-cadherin staining (arrow M-cad+ satellite cell that is also MyoD+ in $\mathbf{A}$, arrowhead $\mathrm{M}$-cad+ satellite cell that remains negative for MyoD in A). C DIC image combined with nuclear staining for DAPI (arrow, arrowhead nuclei of M-cad+ satellite

gastrocnemius muscles of 32-month-old (senile) rats; (2) the increased production of these MRF proteins in 32month-old skeletal muscles is associated with their accumulation in nuclei of both muscle fibers and satellite cells; (3) the up-regulation of MyoD and myogenin protein expression in the nuclei of muscle fibers is most probably related to the insufficiency of motor innervation, whereas the MRF expression in the nuclei of satellite cells is likely to be a sign of their participation in the processes of compensatory myogenesis in presumably denervated and/or re-innervated fibers.

Is a high level of myogenin and/or MyoD protein expression in skeletal muscle a distinguishing feature of aging?

For the last few years, it has been repeatedly shown that the level of MyoD and myogenin mRNA expression is cells in B). D MyoD staining. Note a MyoD+ nucleus of a satellite cell. E M-cadherin staining for $\mathbf{D}$. Note that the MyoD+ satellite cell shows an extension of cytoplasm stretched out along the longitudinal axis of the fiber. F DIC image combined with nuclear staining with DAPI for D. G Myogenin staining. Note that two satellite cells contacting one another have myogenin+ nuclei. H Mcadherin staining for $\mathbf{G}$. Note that $\mathbf{M}$-cadherin demarcates the area of coupling between two myogenin+ satellite cells. I DIC combined with nuclear staining with DAPI for G. Bars $12.5 \mu \mathrm{m}$

higher in the skeletal muscles of old mice than in those of adult mice (Musaro et al. 1995), rats (Marsh et al. 1997; Gomes and Booth 1998; Kostrominova et al. 2000; Alway et al. 2001, 2002; Dedkov et al. 2001), and quails (Lowe et al. 1998). However, only a few studies have assayed the expression of these MRFs at the protein level (Kostrominova et al. 2000; Tamaki et al. 2000; Alway et al. 2001, 2002). In the present study, we have specifically analyzed the levels of MyoD and myogenin protein expression in the gastrocnemius muscles of old (24-, 26-, 28-monthold) and senile (32-month-old) WI/HicksCar rats.

Our data confirm the previous results of Kostrominova et al. (2000) who have demonstrated that the level of myogenin protein expression in the rat gastrocnemius muscle becomes gradually elevated with advancing age in WI/HicksCar rats. In addition, Alway et al. (2001) have also reported that the myogenin protein level is $\sim 314 \%$ higher in the plantaris muscle of 26-month-old rats than in 3 -month-old animals of the Fischer 344 rat strain. In 

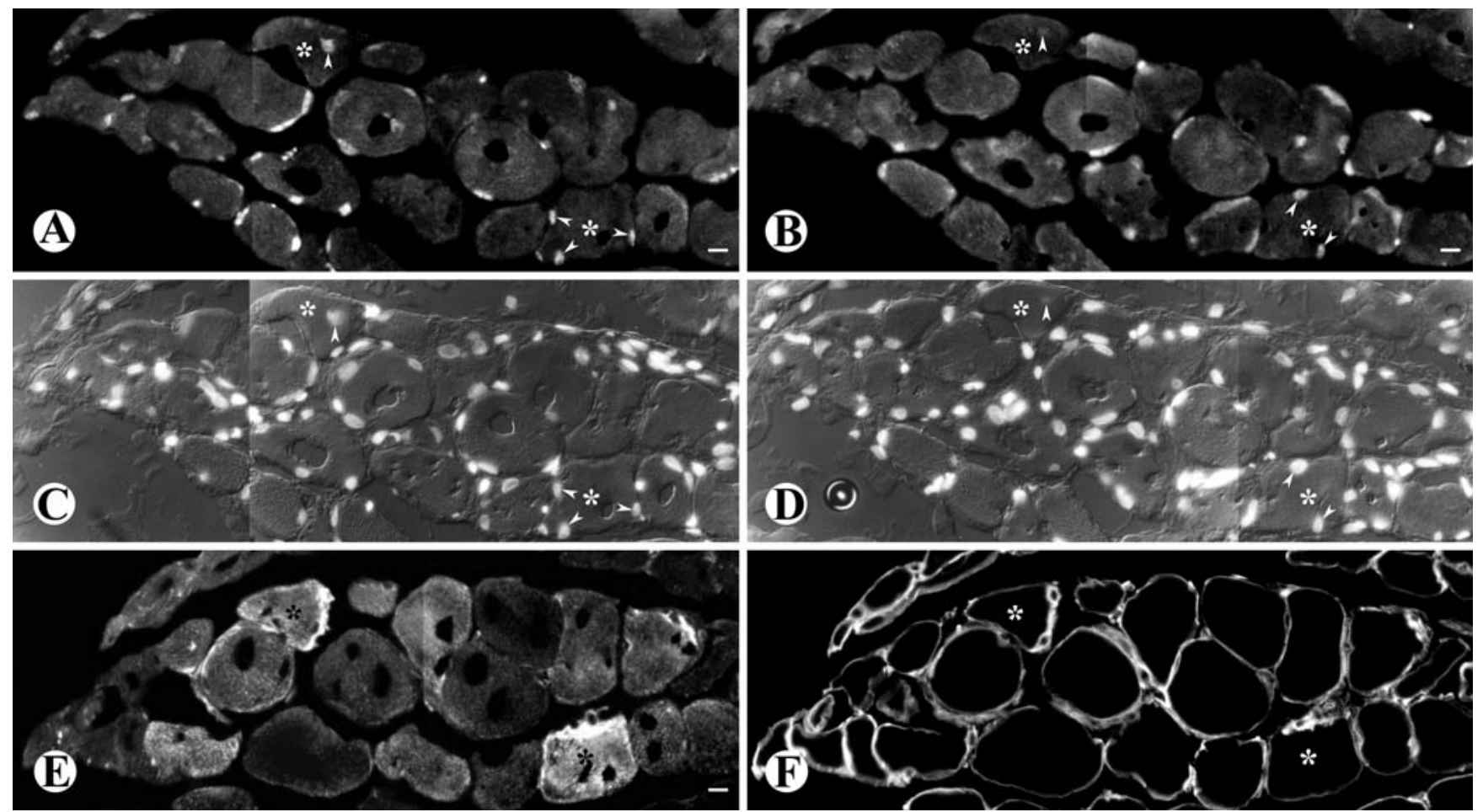

Fig. 10A-F Immunofluorescent photomicrographs from adjacent serial cross sections demonstrating the accumulation of MyoD and/ or myogenin proteins in myonuclei of fibers positively stained for NCAM within a fascicle from 32-month-old EDL muscle (rounded asterisks, straight asterisks two different fibers stained on each image of the muscle fascicle, arrowheads in $\mathbf{A}$ and $\mathbf{C}$, and $\mathbf{B}$ and $\mathbf{D}$ the same myonuclei). Note these two fibers concurrently express

the MyoD and myogenin proteins. A MyoD staining. B Myogenin staining. C DIC image combined with nuclei staining by DAPI for A. D DIC image combined with nuclei staining by DAPI for $\mathbf{B}$. E NCAM staining. Note that NCAM immunoreactivity is present in the plasmalemma and in the cytoplasm of fibers and different degrees of intensity of NCAM expression among fibers within the same fascicle. F Laminin staining for E. Bars $12.5 \mu \mathrm{m}$
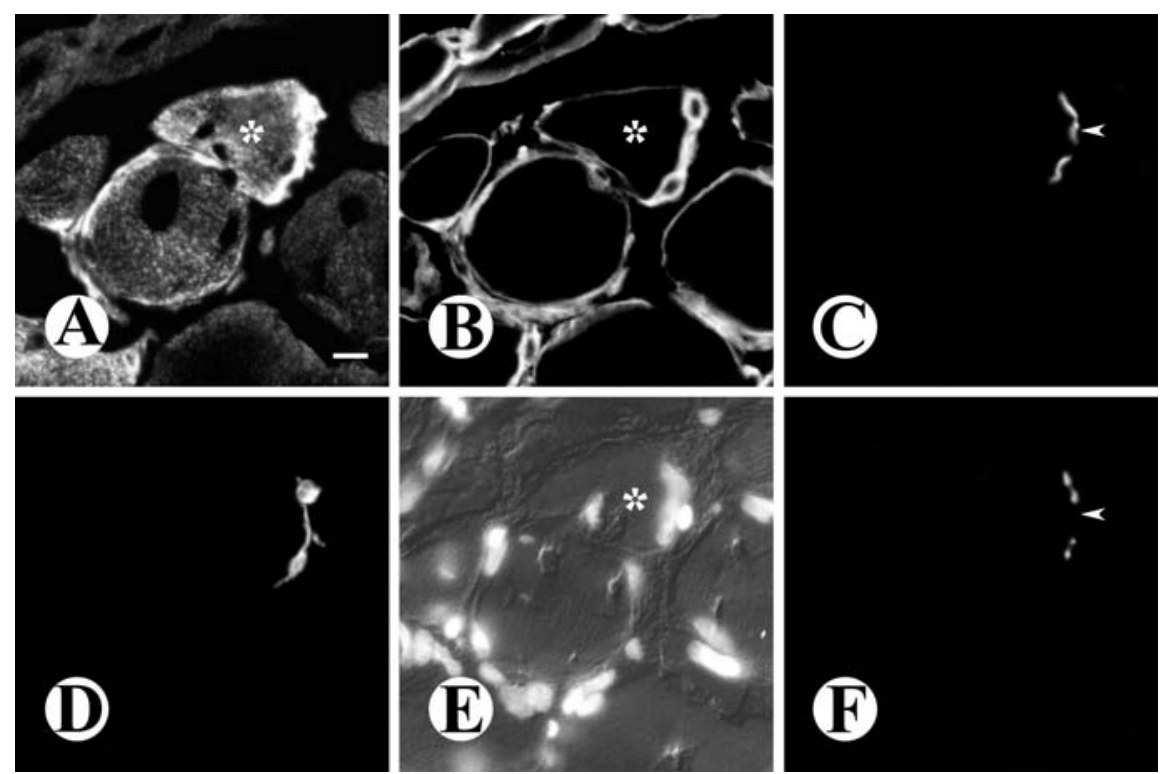

Fig. 11A-F Immunofluorescent photomicrographs from adjacent serial cross sections displaying the partial disruption of axon terminals in the area of a neuromuscular junction of an NCAM+ fiber (asterisk) from 32-month-old EDL muscle. The same fiber indicated on Fig. 10 by a straight asterisk co-expresses MyoD and myogenin. Note that the area on the postsynaptic membrane of the muscle fiber in $\mathbf{C}$ is devoid of an axon terminal in $\mathbf{F}$ (arrowhead). Labeling for S100 protein in D shows the localization of Schwann cells overlying the area of the neuromuscular junction. A NCAM staining. B Laminin staining. C $\alpha$-Bungarotoxin staining. D S100 protein staining. E DIC image combined with nuclei staining by DAPI. F Synaptophysin staining. Bar $12.5 \mu \mathrm{m}$ 

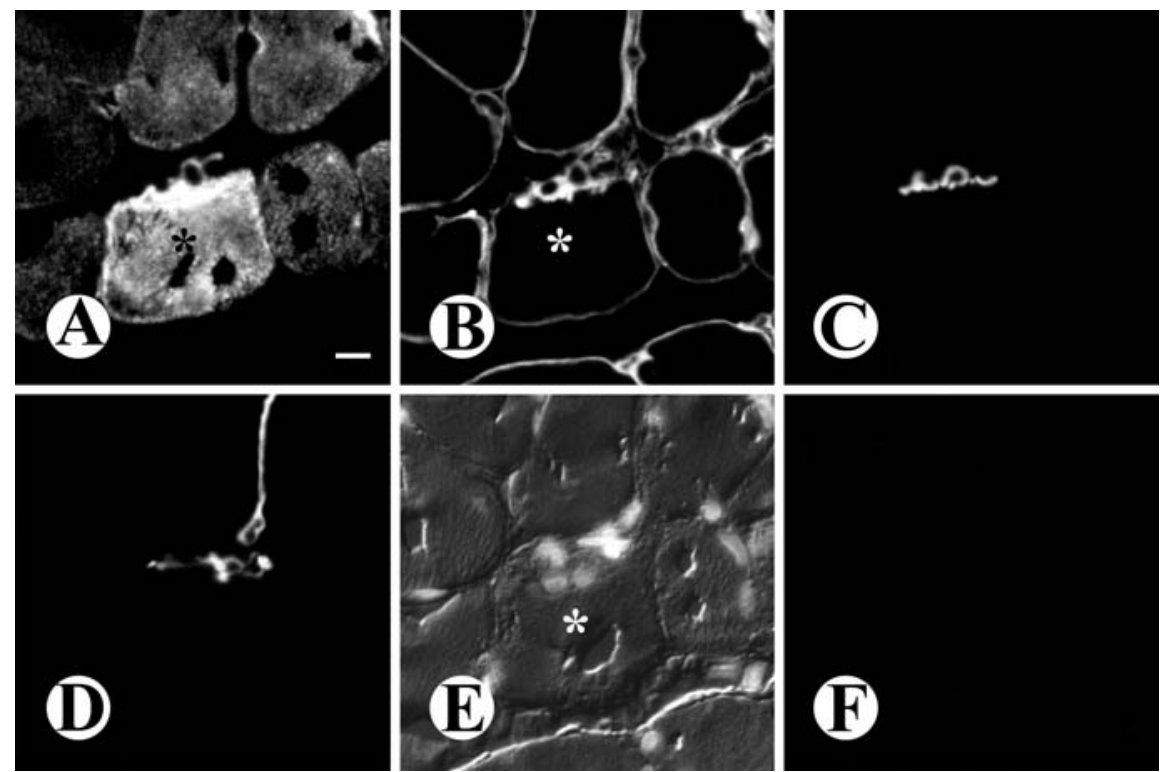

Fig. 12A-F Immunofluorescent photomicrographs from adjacent serial cross sections demonstrating the complete disruption of axon terminals in the area of a neuromuscular junction of an NCAM+ fiber (asterisk) from a 32-month-old EDL muscle. The same fiber indicated in Fig. 10 by a round asterisk co-expresses MyoD and myogenin. Note the entire postsynaptic membrane of the fiber in $\mathbf{C}$ is devoid of axon terminals in F. A NCAM staining. B Laminin staining. C $\alpha$-Bungarotoxin staining. D S100 protein staining. E DIC image combined with nuclei staining by DAPI. F Synaptophysin staining. Bar $12.5 \mu \mathrm{m}$
Fig. 13A-F Immunofluorescent photomicrographs demonstrating, on adjacent serial cross sections of the same fascicle from 32-month-old EDL muscle, an NCAM+ fiber (asterisk) associated with a myogenin+ (activated) satellite cell (arrow). Note that the majority of the myonuclei in surrounding $\mathrm{NCAM}+$ fibers also express myogenin. A Myogenin staining. B M-cadherin staining. C DIC image combined with nuclei staining by DAPI for $\mathbf{A}$ and B. D NCAM staining. E Fast myosin staining. F Slow myosin staining. Bar $12.5 \mu \mathrm{m}$
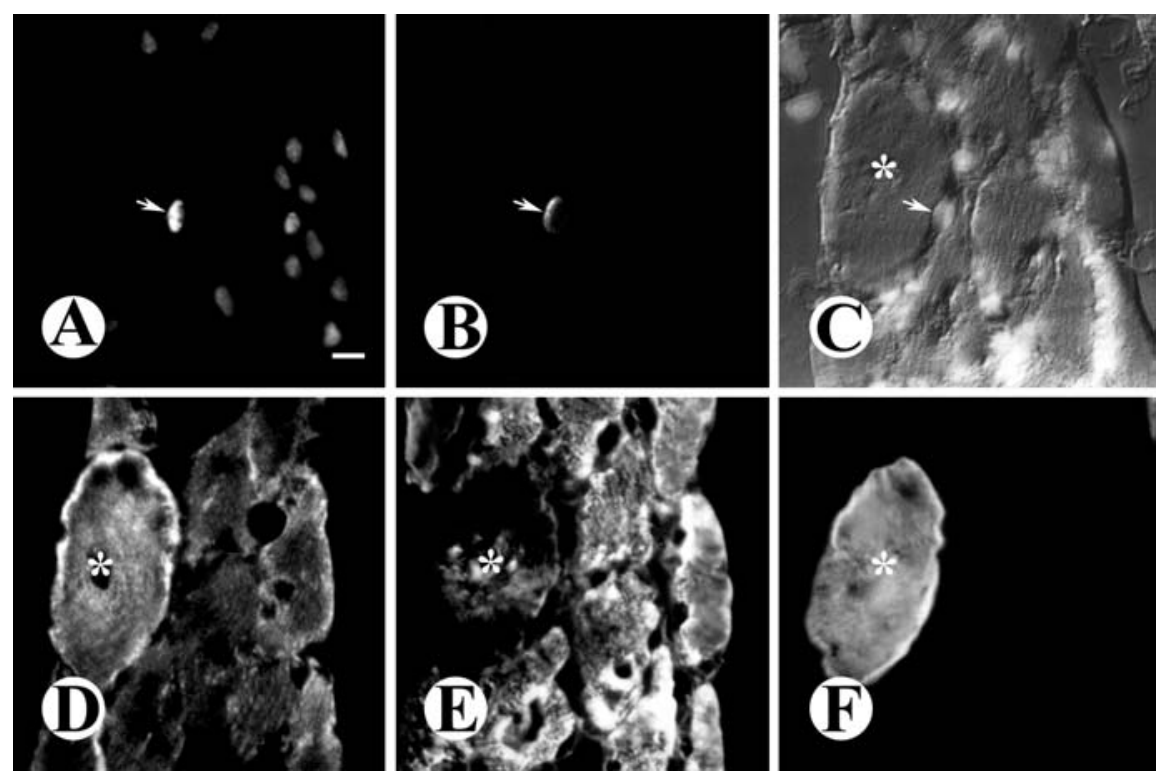

contrast, the same group has recently shown that the protein level of myogenin detected in 37-month-old gastrocnemius and plantaris muscles of Fischer $344 \times$ Brown Norway F1 hybrid rats decreases to $\sim 20 \%$ and $\sim 32 \%$, respectively, of the level recorded in 9-month-old animals (Alway et al. 2002). At the same time, in the soleus muscle from both 26-month-old Fischer 344 rats and 37-month-old Fischer $344 \times$ Brown Norway F1 hybrid rats, the levels of myogenin protein expression are similar to these in young adult animals. We assume that a significant divergence in the results reported in these studies is most likely related to at least three issues: (1) the utilization of rats from different strains, (2) the use of various types of muscles, and (3) significant variation in the age at which the rats from different strains become senescent.

A similar assumption is likely with regard to the study of the level of MyoD protein expression in skeletal muscles of aged animals. For example, Tamaki et al. (2000) have demonstrated that the level of MyoD protein expression decreases in both the plantaris and the soleus muscle of Wistar rats older than 120 weeks of age. On the 
Fig. 14A-F Immunofluorescent photomicrographs demonstrating, on adjacent serial cross sections of the same fascicle from a 32-month-old EDL muscle, an NCAM-negative fiber (asterisk) associated with a myogenin+ (activated) satellite cell (arrow). Note that this fiber expresses fast and slow types of myosin and is located in a fascicle that displays fiber-type grouping. A Myogenin staining. B M-cadherin staining. C DIC image combined with nuclei staining by DAPI for $\mathbf{A}$ and $\mathbf{B}$. D NCAM staining. E Fast myosin staining. F Slow myosin staining. Bar $12.5 \mu \mathrm{m}$
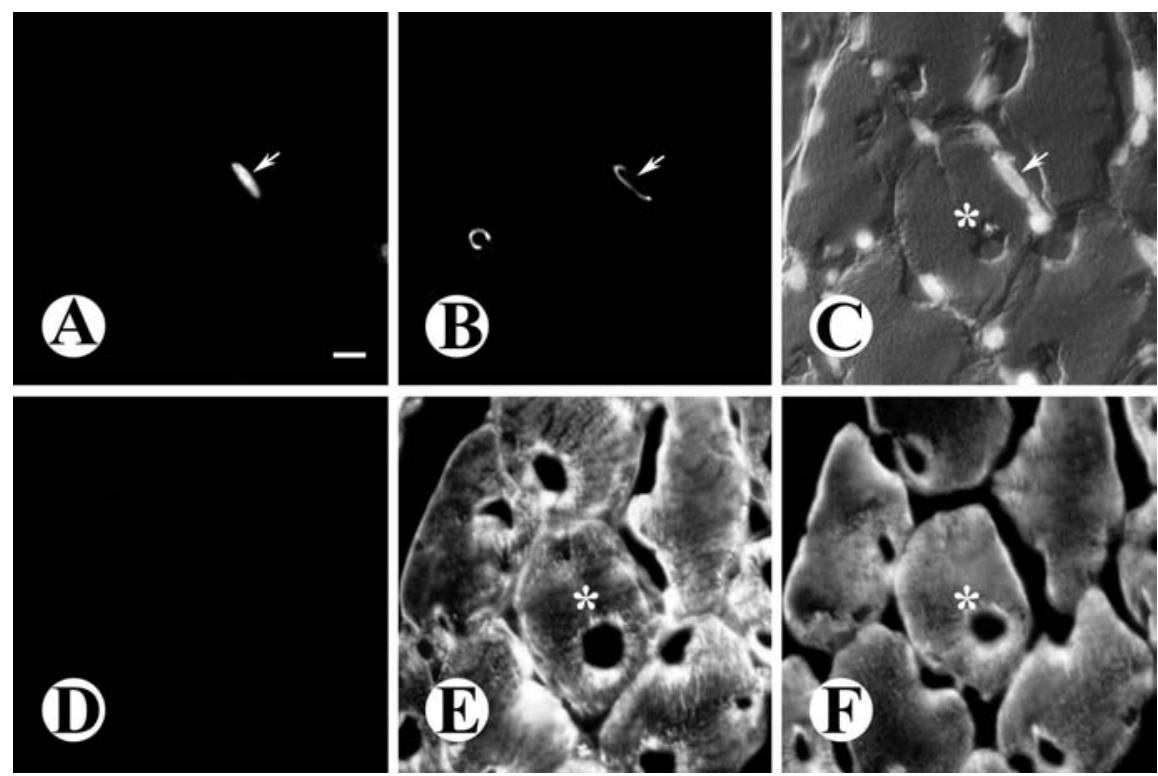

other hand, Alway et al. (2001) have obtained quite different results, showing that the level of MyoD protein expression remains unchanged in 26-month-old plantaris muscles compared with those of 3-month-old animals, whereas it decreases in soleus muscles taken from older members of the same rat strain. However, more recently, the same group has reported that, in plantaris and gastrocnemius muscles of 37-month-old Fischer $344 \times$ Brown Norway F1 hybrid rats, the levels of MyoD protein expression are reduced to $\sim 66 \%$ and $\sim 33 \%$, respectively, of the level in young adult animals, whereas aging had almost no effect on the level of MyoD protein in the soleus muscle of the same rats (Alway et al. 2002). Despite the variance in some results, Alway et al. (2002) have always observed either unchanged or reduced levels of MyoD protein in the various skeletal muscles of aged rats compared with those of young adults.

In studies by Tamaki et al. (2000) and Alway et al. (2001, 2002), the intensity of the $\sim 35-\mathrm{kDa}$ band that corresponds to the predicted molecular mass of the MyoD protein has been analyzed. However, the possibility of the existence of MyoD protein with a molecular weight other than that predicted cannot be eliminated. For example, Tapscott et al. (1988) and Dias et al. (1992) have demonstrated a dephosphorylated form of MyoD protein with a molecular weight about $45-\mathrm{kDa}$ in experiments in vitro. Moreover, Hughes et al. (1997) and Sakuma et al. (1999) have recorded MyoD protein with a molecular weight $\sim 47-48 \mathrm{kDa}$ in young adult skeletal muscles of mice and rats.

In the preliminary experiments for our study, we examined four different anti-MyoD antibodies in the Western blotting (see Materials and methods). We found that, in muscles of aged and young adult rats, all antibodies recognized a single MyoD-specific band with a molecular weight $\sim 43-45 \mathrm{kDa}$ (data not shown). In addition, prominent bands with molecular weights $\sim 55$
$65 \mathrm{kDa}$ showing MyoD-like immunoreactivity were detected in immunoblotting with a polyclonal rabbit anti-MyoD C-20 antibody (see Fig. 3). Three other tested antibodies (two monoclonal and one polyclonal) showed similar, though less intense, immunoreactivity in this area (data not shown). The polyclonal anti-MyoD C-20 antibody was raised against the $\mathrm{C}$-terminus of the $\mathrm{MyoD}$ protein. Taking into account the recent findings of AbuHatoum et al. (1998) and Breitchopf et al. (1998) that the MyoD protein is degraded in cells by the ubiquitin system and that conjugation of MyoD occurs via attachment of ubiquitin to the $\mathrm{N}$-terminus, we hypothesized that an antibody raised against the carboxy terminus of the MyoD protein would be more suitable for the detection of ubiquitinated forms of MyoD in muscle extracts. This is especially appropriate under condition where increased production and degradation of the $\mathrm{MyoD}$ protein in skeletal muscles are anticipated. In order to confirm our hypothesis, we conducted experiments that involved the development of a high level of MyoD protein in muscles, such as direct injury of fibers and denervation of fibers. Under these conditions, the level of MyoD protein production has been previously reported to be increased in fibers and/or satellite cells of muscles (Füchtbauer and Westphal 1992; Weis 1994; Koishi et al. 1995; Creuzet et al. 1998; Cooper et al. 1999). Our data show that immunoblotting of extracts from regenerating, denervated, and aged muscles with the same polyclonal antiMyoD C-20 antibody produces a similar pattern of immunoreactivity. At the same time, this antibody displays no detectable immunoreactivity at molecular weights of $\sim 55-65 \mathrm{kDa}$ in intact muscles of young adult rats, which are known to have a significantly lower degree of $\mathrm{MyoD}$ protein production. Furthermore, according to our results, pre-incubation of a polyclonal anti-MyoD C-20 antibody with a recombinant MyoD protein markedly diminishes the immunoreactivity in both MyoD- 
specific (43-45 kDa) and MyoD-like (55-65 kDa) bands in Western blots of senile skeletal muscle. Therefore, we conclude that the occurrence of the MyoD-like bands with a higher than expected molecular weight in aged muscle is the result of MyoD protein modification (most likely ubiquitination). As the presence of phosphorylated, acetylated, and ubiquitinated forms of MyoD have been established in skeletal muscles (for a review, see Puri and Sartorelli 2000), further investigations are necessary to address the nature of MyoD protein modification in muscles of aged animals.

Our results have shown that, whereas the level of MyoD protein with a molecular weight $\sim 43-45 \mathrm{kDa}$ is similar between muscles from young adult and aged rats, the level of MyoD-like immunoreactivity within the 55to $65-\mathrm{kDa}$ bands demonstrates steady enhancement with aging. This finding of an increased production of MyoD protein in muscles of aged rats is in agreement with the results of other investigators who have previously reported that the level of MyoD mRNA expression gradually increases in skeletal muscles of senescent animals.

Do muscle fibers and satellite cells both contribute to the elevated level of MyoD and myogenin protein expression in aged skeletal muscles?

Adult skeletal muscle tissue consists of two major cell populations: muscle fibers and satellite cells. Both of these cell populations might express MRF proteins under certain conditions. It would be logical to suggest that each group of cells is able to contribute discretely to MyoD and/or myogenin protein production in aged skeletal muscles. However, only a limited number of studies have made attempts to determine the exact source of MyoD and/or myogenin protein expression in skeletal muscles by techniques that allow the expression of these MRF proteins to be distinguished differentially in the nuclei of muscle fibers and satellite cells (Koishi et al. 1995; Dupont-Versteegden et al. 1998; Cooper et al. 1999).

In the studies by Koishi et al. (1995) and DupontVersteegden et al. (1998), satellite cells have been distinguished indirectly by using a labeling technique with antibodies against dystrophin and either MyoD or myogenin. When the plasma membrane of a muscle fiber becomes delineated with anti-dystrophin antibody, a MyoD+ or myogenin+ profile of a satellite cell nucleus lies outside the muscle fiber plasmalemma. However, this technique does not always permit differentiation between the nuclei of satellite cells and muscle fibers. At the lightmicroscope level, it would be difficult or even impossible to determine whether a dystrophin-positive plasmalemma of a fiber separates a peripheral myonucleus and satellite cell nucleus, which may be contiguous one to another. Cooper et al. (1999) are the only ones who have used a labeling technique that permits the MyoD+ nucleus of a satellite cell and the MyoD+ myonucleus of a fiber to be distinguished directly. In their study, the antibody against
M-cadherin was utilized on regenerating gastrocnemius and soleus muscles of mice in order to identify the activated satellite cells. The effectiveness of M-cadherin immunodetection as the marker of quiescent and activated satellite cells in skeletal muscle of rodents has been repeatedly confirmed (Irintchev et al. 1994; Kaufmann et al. 1999; Hawke and Garry 2001). In our study, we have also demonstrated that a double-staining technique with antibodies against M-cadherin and either MyoD or myogenin allows the differentiation of MRF protein expression in the nuclei of muscle fibers and satellite cells within skeletal muscles of senile rats.

Over the past decade, only two studies have examined myogenin protein accumulation in the nuclei of old muscle fibers (Musaro et al. 1995; Kostrominova et al. 2000). No attempts have been made in these studies to determine whether satellite cells contribute to the production of MRF proteins. Furthermore, before our study, no efforts had been made to identify the source of the MyoD protein expression in skeletal muscles of old rats. The data presented in our study reveal that MyoD and myogenin proteins are accumulated in the nuclei of both muscle fibers and satellite cells of 32-month-old skeletal muscle of rats.

Is the accumulation of MyoD and myogenin proteins in fibers and satellite cells associated with existing processes of muscle denervation and/or myogenesis in senile muscles?

There is considerable evidence that a significant increase of MyoD and myogenin production in adult skeletal muscles can be provoked by experimental conditions, such as the interruption of motor innervation or by the damage of muscle fibers. Under these circumstances, the accumulation of MyoD and/or myogenin occurs at the $\mathrm{mRNA}$ and/or protein levels in the nuclei of denervated muscle fibers (Weis 1994; Koishi et al. 1995; DupontVersteegden et al. 1998; Kostrominova et al. 2000; Dedkov et al. 2001) and in the nuclei of activated satellite cells (or myoblasts; Füchtbauer and Westphal 1992; Grounds et al. 1992; Weis 1994; Kami et al. 1995; Koishi et al. 1995; Creuzet et al. 1998; Dupont-Versteegden et al. 1998; Cooper et al. 1999; Launay et al. 2001).

According to our ultrastructural and immunohistochemical investigations, the skeletal muscles from 32month-old rats possess fibers with compromised motor innervation (Figs. 5, 11, 12). In support of our current findings, a previous experimental study conducted on aged animals from the same rat strain (Carlson et al. 2001) also showed evidence of fiber denervation in intact EDL muscles. These observations strengthen the view that the age-related "physiological" denervation of fibers might be a significant part of the changes that occur in skeletal muscles with advancing age (Fujisawa 1974; Caccia et al. 1979; Larsson 1982; Carlson 1995).

In our study, we have found that fibers demonstrating a deficiency in motor innervation are positively stained for 
NCAM protein. This observation is in accordance with the results of other investigators who have previously reported that injury of the motor axons and chemical blockage of either nerve conduction or pre-synaptic release of neurotransmitters induces the up-regulation of NCAM protein expression in fibers of skeletal muscle from adult rodents (Daniloff et al. 1986; Moore and Walsh 1986; Sanes et al. 1986). Considering that the $\mathrm{NCAM}+$ fibers were presumably partially or completely denervated, we decided to study whether either MyoD or myogenin protein expression was present in such fibers. We showed that the majority of NCAM+ fibers from 32month-old EDL muscles had MyoD+ and/or myogenin+ nuclei. Our observations support the view that some of MyoD+ and myogenin+ fibers in senile muscles of WI/ HicksCar rats have a deficient motor innervation. However, a complete understanding of the mechanisms that might be responsible for the up-regulation of MyoD and myogenin in aged muscle fibers remains to be elucidated.

The presence of activated satellite cells associated with undamaged fibers was detected at the ultrastructural level in skeletal muscle from 32-month-old rats. We also found that some satellite cells in senile muscles expressed either MyoD or myogenin proteins, whereas quiescent satellite cells from muscles of 4-month-old rats remained immunonegative for both MRFs. As MyoD is required for determination of myogenic precursor cells, whereas myogenin acts downstream of MyoD during myoblast differentiation in the course of embryonic myogenesis (Neville and Rosenthal 1996; Sabourin and Rudnicki 2000), we assume that the occurrence of MRF protein expression in the satellite cells of aged muscles is one of the features of their activation. In agreement with our data, several other studies have indicated that satellite cells in intact muscles of young adult rodents are immunonegative for $\mathrm{MyoD}$ and myogenin proteins (Füchtbauer and Westphal 1992; Koishi et al. 1995; Creuzet et al. 1998; Cooper et al. 1999). In contrast, the activated satellite cells from damaged (Füchtbauer and Westphal 1992; Koishi et al. 1995; Creuzet et al. 1998; Cooper et al. 1999) or denervated (Weis 1994; DupontVersteegden et al. 1998) muscles accumulate MyoD and/ or myogenin proteins. Since cells with characteristics of true myoblasts have never been seen at the ultrastructural level in muscles from senile rats, we prefer to call all MyoD+ and myogenin+ cells as activated satellite cells. However, a question concerning the distinctive nature of MyoD+ and myogenin+ cells within uninjured senile muscles remains open. Whether these cells are indeed activated satellite cells or whether they are the previously differentiated descendants of quiescent satellite cells, such as myoblasts, needs to be investigated.

In our study of 32-month-old EDL muscles, we have obtained no evidence that activated satellite cells are associated with degenerating muscle fibers. Based on this observation, we suggest that compensatory myogenesis in the living fibers might be a process that is most likely responsible for the initiation of the myogenic program in satellite cells of senile skeletal muscles. Our findings also show that most of the fibers that are associated with MyoD+ or myogenin+ satellite cells demonstrate a phenotype characteristic of fibers that either currently have or in the past had a deficiency in motor innervation and subsequent fiber atrophy. Based on these data, we suggest that satellite cells located on the surface of denervated (or re-innervated) fibers from 32-month-old EDL muscle might become activated and be able to participate in the processes of compensatory myogenesis.

Similarly, Schmalbruch and Lewis (2000) have reported that muscle denervation leads to the fusion of activated satellite cells with denervated fibers in order to compensate for a significant loss of myonuclei. Interestingly, at the ultrastructural level, the activated satellite cells of the 32-month-old muscles in our study occasionally demonstrate features characteristic of the process of the fusion of cells with living fibers (Figs. 5D, 6C, D). Robertson et al. (1990) have previously described similar ultrastructural findings regarding the fusion between myogenic cells and fibers within regenerating muscles of adult mice.

In summary, our observations suggest that partial or complete denervation of myofibers and participation of satellite cells in compensatory myogenesis might both be responsible for the up-regulation of the level of MyoD and myogenin protein expression in hindlimb skeletal muscles of 32-month-old WI/HicksCar rats.

\section{References}

Abu-Hatoum O, Gross-Mesilaty S, Breitschopf K, Hoffman A, Gonen H, Ciechanover A, Bengal E (1998) Degradation of myogenic transcription factor MyoD by the ubiquitine pathway in vivo and in vitro: regulation by specific DNA binding. Mol Cell Biol 18:5670-5677

Adams L, Carlson BM, Henderson L, Goldman D (1995) Adaptation of nicotinic acetylcholine receptor, myogenin, and MRF4 gene expression to long-term muscle denervation. J Cell Biol 131:1341-1349

Alway SE, Lowe DA, Chen KD (2001) The effects of age and hindlimb suspension on the levels of expression of the myogenic regulatory factors $\mathrm{MyoD}$ and myogenin in rat fast and slow skeletal muscles. Exp Physiol 86:509-517

Alway SE, Degens H, Lowe DA, Krishnamurthy G (2002) Increased myogenic repressor Id mRNA and protein levels in hindlimb muscles of aged rats. Am J Physiol Regul Integrative Comp Physiol 282:R411-R422

Breitschopf K, Bengal E, Ziv T, Admon A, Ciechanover A (1998) A novel site for ubiquitination: the N-terminal residue, and not internal lysines of $\mathrm{MyoD}$, is essential for conjugation and degradation of the protein. EMBO J 17:5964-5973

Buonanno A, Cheng J, Venepally P, Weis J, Calvo S (1998) Activity-dependent regulation of muscle genes: repressive and stimulatory effects of innervation. Acta Physiol Scand 163:S17-S26

Caccia MR, Harris JB, Johnson MA (1979) Morphology and physiology of skeletal muscle in aging rodents. Muscle Nerve 2:202-212

Carlson BM (1995) Factors influencing the repair and adaptation of muscles in aged individuals: satellite cells and innervation. J Gerontol Biol Sci 50A:96-100

Carlson BM, Dedkov EI, Borisov AB, Faulkner JA (2001) Skeletal muscle regeneration in very old rats. J Gerontol Biol Sci 56A:B224-B233 
Cooper RN, Tajbakhsh S, Mouly V, Cossu G, Buckingham M, Butler-Browne GS (1999) In vivo satellite cell activation via Myf5 and MyoD in regenerating mouse skeletal muscle. J Cell Sci 112:2895-2901

Creuzet S, Lescaudron L, Li Z, Fontaine-Perus J (1998) MyoD, myogenin, and desmin-nls-lacZ transgene emphasize the distinct patterns of satellite cell activation in growth and regeneration. Exp Cell Res 243:241-253

Daniloff JK, Levi G, Grumet M, Rieger F, Edelman GM (1986) Altered expression of neuronal cell adhesion molecules induced by nerve injury and repair. J Cell Biol 103:929-945

Dedkov EI, Kostrominova TY, Borisov AB, Carlson BM (2001) Reparative myogenesis in long-term denervated skeletal muscles of adult rats results in a reduction of the satellite cell population. Anat Rec 263:139-154

Dias P, Parham DM, Shapiro DN, Tapscott SJ, Houghton PJ (1992) Monoclonal antibodies to the myogenic regulatory protein MyoD1: epitope mapping and diagnostic utility. Cancer Res 52:6431-6439

Duclert A, Piette J, Changeux J-P (1991) Influence of innervation of myogenic factors and acetylcholine receptor $\alpha$-subunit mRNAs. NeuroReport 2:25-28

Dupont-Versteegden EE, Houle JD, Gurley CM, Peterson CA (1998) Early changes in muscle fiber size and gene expression in response to spinal cord transection and exercise. Am J Physiol Cell Physiol 275:C1124-C1133

Edmondson DG, Olson EN (1993) Helix-loop-helix proteins as regulators of muscle-specific transcription. J Biol Chem 268:755-758

Eftimie R, Brenner HR, Buonanno A (1991) Myogenin and MyoD join a family of skeletal muscle genes regulated by electrical activity. Proc Natl Acad Sci USA 88:1349-1353

Faulkner JA, Brooks SV, Zebra E (1995) Muscle atrophy and weakness with aging: contraction-induced injury as an underlying mechanism. J Gerontol Biol Sci 50A:124-129

Füchtbauer E-M, Westphal H (1992) MyoD and myogenin are coexpressed in regenerating skeletal muscle of the mouse. Dev Dyn 193:34-39

Fujisawa K (1974) Some observations on the skeletal musculature of aged rats. J Neurol Sci 22:353-366

Funk WD, Ouellette M, Wright WE (1991) Molecular biology of myogenic regulatory factors. Mol Biol Med 8:185-195

Gomes RR Jr, Booth FW (1998) Expression of acetylcholine receptor mRNAs in atrophying and non-atrophying skeletal muscles of old rats. J Appl Physiol 85:1903-1908

Grounds MD, Garrett KL, Lai MC, Wright WE, Beilharz MW (1992) Identification of skeletal muscle precursor cells in vivo by use of MyoD1 and myogenin probes. Cell Tissue Res 267:99-104

Hawke TJ, Garry DJ (2001) Myogenic satellite cells: physiology to molecular biology. J Appl Physiol 91:534-551

Hughes SM, Koishi K, Rudnicki M, Maggs AM (1997) MyoD protein is differentially accumulated in fast and slow skeletal muscle fibers and required for normal fiber type balance in rodents. Mech Dev 61:151-163

Irintchev A, Zeschnigk M, Starzinski-Powitz A, Wernig A (1994) Expression pattern of M-cadherin in normal, denervated, and regenerating mouse muscles. Dev Dyn 199:326-337

Kami K, Noguchi K, Senba E (1995) Localization of myogenin, cfos, c-jun, and muscle-specific gene mRNAs in regenerating rat skeletal muscle. Cell Tissue Res 280:11-19

Kaufmann U, Martin B, Link D, Witt K, Zeitler R, Reinhard S, Starzinski-Powitz A (1999) M-cadherin and its sisters in development of striated muscle. Cell Tissue Res 296:191-198

Koishi K, Zhang M, McLennan IS, Harris AJ (1995) MyoD protein accumulates in satellite cells and is neurally regulated in regenerating myotubes and skeletal muscle fibers. Dev Dyn 202:244-254

Kostrominova TY, Macpherson PCD, Carlson BM, Goldman D (2000) Regulation of myogenin protein expression in dener- vated muscles from young and old rats. Am J Physiol Regul Integrative Comp Physiol 279:R179-R188

Larsson L (1982) Aging in mammalian skeletal muscle. In: Mortimer JA, Pirozzolo FJ, Maletta GJ (eds) The aging motor system. Praeger, New York, pp 60-97

Larsson L, Ramamurthy B (2000) Aging-related changes in skeletal muscle. Drugs Aging 17:303-316

Launay T, Armand A-S, Charbonnier F, Mira J-C, Donsez E, Gallien CL, Chanoine C (2001) Expression and neural control of myogenic regulatory factor genes during regeneration of mouse soleus. J Histochem Cytochem 49:887-899

Lowe DA, Lund T, Always SE (1998) Hypertrophy-stimulated myogenic regulatory factor mRNA increases are attenuated in fast muscle of aged quails. Am J Physiol 275 (Cell Physiol 44):C155-C162

Marsh DR, Criswell DS, Carson JA, Booth FW (1997) Myogenic regulatory factors during regeneration of skeletal muscle in young, adult, and old rats. J Appl Physiol 83:1270-1275

Moore SE, Walsh FS (1986) Nerve dependent regulation of neural cell adhesion molecule expression in skeletal muscle. Neurosci 18:499-505

Musaro A, Cusella De Angelis MG, Germani A, Ciccarelli C, Molinaro M, Zani BM (1995) Enhanced expression of myogenic regulatory genes in aging skeletal muscle. Exp Cell Res 221:241-248

Navarro A, Lopez-Cepero JM, Sanchez del Pino MJ (2001) Skeletal muscle and aging. Front Biosci 6:D26-D44

Neville C, Rosenthal N (1996) Transcriptional regulation of skeletal myogenesis. In: Goodbourn S (ed) Eukariotic gene transcription. Oxford University Press, Oxford, pp 192-233

Puri PL, Sartorelli V (2000) Regulation of muscle regulatory factors by DNA-binding, interacting proteins, and post-transcriptional modifications. J Cell Physiol 185:155-173

Robertson TA, Grounds MD, Mitchell CA, Papadimitriou JM (1990) Fusion between myogenic cells in vivo: an ultrastructural study in regenerating murine skeletal muscle. J Struct Biol 105:170-182

Sabourin LA, Rudnicki MA (2000) The molecular regulation of myogenesis. Clin Genet 57:16-25

Sakuma K, Watanabe K, Sano M, Uramoto I (1999) The adaptive response of MyoD family proteins in overloaded, regenerating and denervated rat muscles. Biochim Biophys Acta 1428:284292

Sanes JR, Schachner M, Covault J (1986) Expression of several adhesive macromolecules (N-CAM, L1, J1, NILE, uvomorulin, laminin, fibronectin, and a heparan sulfate proteoglycan) in embryonic, adult, and denervated adult skeletal muscle. J Cell Biol 102:420-431

Schmalbruch H, Lewis DM (2000) Dynamics of nuclei of muscle fibers and connective tissue cells in normal and denervated rat muscles. Muscle Nerve 23:617-626

Tamaki T, Uchiyama S, Uchiyama Y, Akatsuka A, Yoshimura S, Roy RR, Edgerton VR (2000) Limited myogenic response to a single bout of weight-lifting exercise in old rats. Am J Physiol Cell Physiol 278:C1143-C1152

Tapscott SJ, Davis RL, Thayer MJ, Cheng P-F, Weintraub H, Lassar AB (1988) MyoD1: a nuclear phosphoprotein requiring a myc homology region to convert fibroblasts to myoblasts. Science 242:405-411

Voytik SL, Przyborski M, Badylak SF, Konieczny SF (1993) Differential expression of muscle regulatory factor genes in normal and denervated adult rat hindlimb muscles. Dev Dyn 198:214-224

Weis J (1994) Jun, Fos, MyoD1 and myogenin proteins are increased in skeletal muscle fiber nuclei after denervation. Acta Neuropathol 87:63-70

Witzemann V, Sakmann B (1991) Differential regulation of MyoD and myogenin mRNA levels by nerve induced muscle activity. FEBS Lett 282:259-264 